OPEN ACCESS

Edited by: Stephanie Ma,

The University of Hong Kong,

Hong Kong

Reviewed by:

Gianpaolo Papaccio,

Second University of Naples, Italy

Kwan Ho Tang,

New York University, United States

${ }^{*}$ Correspondence:

Terence Kin Wah Lee

terence.kw.lee@polyu.edu.hk

Specialty section

This article was submitted to

Stem Cell Research,

a section of the journal

Frontiers in Cell and Developmental

Biology

Received: 09 April 2021

Accepted: 31 May 2021

Published: 21 June 2021

Citation:

Lei MML and Lee TKW (2021)

Cancer Stem Cells: Emerging Key

Players in Immune Evasion

of Cancers.

Front. Cell Dev. Biol. 9:692940.

doi: 10.3389/fcell.2021.692940

\section{Cancer Stem Cells: Emerging Key Players in Immune Evasion of Cancers}

\author{
Martina Mang Leng Lei ${ }^{1}$ and Terence Kin Wah Lee ${ }^{1,2 *}$ \\ ${ }^{1}$ Department of Applied Biology and Chemical Technology, The Hong Kong Polytechnic University, Kowloon, Hong Kong, \\ ${ }^{2}$ State Key Laboratory of Chemical Biology and Drug Discovery, The Hong Kong Polytechnic University, Kowloon, \\ Hong Kong
}

Cancer stem cells (CSCs) are subpopulations of undifferentiated cancer cells within the tumor bulk that are responsible for tumor initiation, recurrence and therapeutic resistance. The enhanced ability of CSCs to give rise to new tumors suggests potential roles of these cells in the evasion of immune surveillance. A growing body of evidence has described the interplay between CSCs and immune cells within the tumor microenvironment (TME). Recent data have shown the pivotal role of some major immune cells in driving the expansion of CSCs, which concurrently elicit evasion of the detection and destruction of various immune cells through a number of distinct mechanisms. Here, we will discuss the role of immune cells in driving the stemness of cancer cells and provide evidence of how CSCs evade immune surveillance by exerting their effects on tumor-associated macrophages (TAMs), dendritic cells (DCs), myeloidderived suppressor cells (MDSCs), T-regulatory (Treg) cells, natural killer (NK) cells, and tumor-infiltrating lymphocytes (TILs). The knowledge gained from the interaction between CSCs and various immune cells will provide insight into the mechanisms by which tumors evade immune surveillance. In conclusion, CSC-targeted immunotherapy emerges as a novel immunotherapy strategy against cancer by disrupting the interaction between immune cells and CSCs in the TME.

Keywords: cancer, cancer stem cells, immune cells, tumor microenvironment, immune evasion

\footnotetext{
Abbreviations: ADCC, antibody-dependent cellular cytotoxicity; CSC, cancer stem cell; CCL, C-C motif chemokine ligand; CAR, chimeric antigen receptor; CHI3L1, chitinase 3-like 1; CXCR, C-X-C motif chemokine receptor; CXCL, C-XC motif ligand; CTL, cytotoxic T cell; CTLA-4, cytotoxic T-lymphocyte-associated protein-4; DC, dendritic cell; EMT, epithelial-mesenchymal transition; FTO, fat mass and obesity-associated protein; HCC, hepatocellular carcinoma; HMA, hypomethylating agents; IFN- $\gamma$, interferon gamma; gMDSC, granulocytic MDSC; IL, interleukin; MSC, mesenchymal stem cell; mMDSC, monocytic MDSC; MDSC, myeloid-derived suppressor cell; m6A, N6-methyladenosine; NK, natural

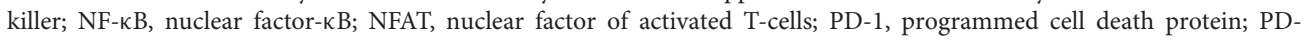
L1, programmed death-ligand 1; PGE2, prostaglandin E2; Siglec-10, sialic-acid-binding Ig-like lectin 10; SIPR $\alpha$, signal regulatory protein alpha; STAT3, signal transducer and activator of transcription 3; TIM-3, T cell immunoglobulin and mucin domain-containing protein-3; Th cell, Thelper cell; TGF- $\beta$, transforming growth factor beta; Treg, T regulatory; TAM, tumor associated macrophage; TIL, tumor-infiltrating lymphocyte; TME, tumor microenvironment; TNF- $\alpha$, tumor necrosis factor-alpha; VEGF, vascular endothelial growth factor.
} 


\section{INTRODUCTION}

Cancer stem cells (CSCs) are subsets of cancer cells enriched with stem cell-like characteristics, including self-renewal ability and multilineage differentiation (Bhatia and Kumar, 2016). The CSC theory of tumor progression presents the tumor microenvironment (TME) as a hierarchically organized tissue with a CSC subpopulation ranked at the top level, which generates more differentiated cancer cells with lower or limited proliferative potential. CSCs are often defined by the expression of surface stem cell markers such as CD24, CD34, CD44, CD47, CD133, and CD90, along with side populations that can be isolated and enriched in vitro and in vivo without stem cell surface markers (Taniguchi et al., 2019). Epithelial-tomesenchymal transition (EMT) is well known to be an inducer of CSC phenotypes via epigenetic regulation (Bocci et al., 2019). Its activation allows CSCs to drive resistance to conventional therapy and thus leads to treatment relapse and tumor reoccurrence (Shibue and Weinberg, 2017).

A substantial body of literature has extensively described the interactions of tumor bulks with the immune system; however, investigations have only begun to elucidate the relationship of CSCs and immune cells within the TME, paving the way for the development of rational therapeutic strategies to explore CSCimmune dynamics. The capability of CSCs in tumor initiation in partly immunocompromised mice e.g., SCID or NOD/SCID mice ( $\mathrm{T}, \mathrm{B}$ cells defect but NK cells present) suggests that these cells are empowered with the definitive ability to evade immune detection and surveillance, whereas non-CSCs require a higher extent of deficiency in immune system for generating tumors in NSG mice (lack of T, B, and NK cells) (Tsuchiya and Shiota, 2021). Increasing evidence has demonstrated that there is a reciprocal interaction between CSCs and various immune cells. Major immune cells within the TME drive CSC expansion and concurrently elicit protumorigenic immune cell activities, promoting CSC-specific avoidance of immune detection and destruction. In this section, we will discuss the emerging knowledge of the role of tumor-associated macrophages (TAMs), dendritic cells (DCs), myeloid-derived suppressor cells (MDSCs), $\mathrm{T}$ regulatory (Treg) cells, natural killer (NK) cells, and tumorinfiltrating lymphocytes (TILs) in driving cancer stemness and how CSCs evade the immune surveillance of these cells. Finally, we will discuss the potential of CSC-targeted immunotherapy to eradicate cancer.

\section{TUMOR-ASSOCIATED MACROPHAGES}

Macrophages can be classified into two subtypes: proinflammatory M1 and anti-inflammatory M2 macrophages (Chen et al., 2019). TAMs usually express an M2 phenotype, which executes immunosuppressive and pro-tumor functions and is thus closely related to cancer progression and recurrence (Lewis and Pollard, 2006; Malfitano et al., 2020).

Developing findings support the hypothesis that CSCs influence the immune TME via the recruitment of macrophages and the promotion of their pro-tumor properties, while TAMs, in turn, are crucial for the self-renewal ability and maintenance of CSCs in primary tumors through the coupling between STAT3 and NF-кB signaling cascades (Sainz et al., 2016). It has been proposed that CSCs have an intrinsic immunosuppressive program involving recruiting macrophages and driving them toward M2 polarization at the tumor site (Brissette et al., 2012). This ability of CSCs is commonly found in ovarian, glioblastoma, liver, breast and lung cancers through activating the signal transducer and activator of transcription 3 (STAT3) and nuclear factor- $\kappa \mathrm{B}(\mathrm{NF}-\kappa \mathrm{B})$ pathways and cytokines such as interleukin (IL)-8 and IL-10 (Iliopoulos et al., 2009; Ginestier et al., 2010; Mitchem et al., 2013; Fang et al., 2014). For example, in hepatocellular carcinoma (HCC), $\mathrm{CD}_{133}{ }^{+}$cells induce M2 polarization of TAMs through secretion of IL-8 (Xiao et al., 2018). In glioblastoma, CSCs generate higher levels of the chemoattractants C-C motif chemokine ligand 2 (CCL2), CCL5, vascular endothelial growth factor-A (VEGF-A), and neurotensin than the bulk of the glioma (Yi et al., 2011). The extracellular matrix protein periostin is preferentially expressed

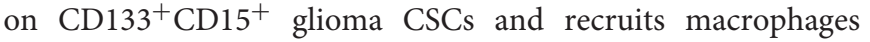
through integrin $\alpha v \beta 3$ from the peripheral blood to the brain (Zhou et al., 2015). Depletion of periostin in glioma CSCs leads to a reduction in the M2 population and alleviates tumor growth in glioblastoma xenografts. In breast cancer, Sox $2^{+}$cancer cells, via activation of nuclear factor of activated T-cells (NFAT), STAT3 and NF- $\kappa$ B, express chemokines CCL3 and ICAM-1 and thus recruit TAMs into the TME (Yang et al., 2013; Mou et al., 2015). These findings suggest that CSCs play an important role in TAM recruitment and $\mathrm{M} 2$ polarization by secreting macrophage chemoattractants.

Subsequent to TAM recruitment to the TME, TAMs are deployed as a "niche" to support CSC growth. Infiltrating TAMs, by activating the NF- $\kappa \mathrm{B}$ signaling pathway, secrete the inflammatory cytokines IL-1 $\beta$, IL-6, IL-10, transforming growth factor beta (TGF- $\beta$ ), and MFG-E8 (Jinushi et al., 2011; Li et al., 2012; Fang et al., 2014; Wan et al., 2014; Yang et al., 2019). These tumor-promoting cytokines bind to their receptors, further stimulating STAT3 activation in adjacent CSCs. This results in a vicious cycle of NF- $\kappa \mathrm{B}$ activation as well as stemness maintenance of cancer cells. For example, treatment of breast cancer cells with conditioned medium of TAMs leads to increments in the stem cell markers Sox-2, Oct3/4 and Nanog with enhanced ALDH1 activity in a mouse model (Nnv and Kundu, 2018). The abrogation of STAT3 confirmed the role of JAK/STAT pathway in mediating TAM regulation on CSC enrichment. In coculture systems, recruited TAMs promote liver CSC expansion through IL-6/STAT3, Wnt/ $\beta$-catenin and TGF- $\beta$ signaling pathways (Fang et al., 2014; Wan et al., 2014; Chen et al., 2019). TAMs preferentially secrete TGF- $\beta$ to stimulate CSC-like properties by inducing EMT, while TAM-derived IL- 6 induces CD $44^{+}$ HCC stem cell expansion by activating STAT3, thus promoting tumor development through CSC growth. Blockade of IL-6 with tocilizumab and STAT3 knockdown attenuated CD44 ${ }^{+}$sphere formation and tumor growth of patient-derived HCC as well as breast xenografts (Wan et al., 2014; Wang et al., 2018a).

To facilitate communication, TAMs establish direct adhesion with $\mathrm{CD}^{+} 0^{+} \mathrm{CSC}$ through EphA/ephrin A signaling and 
promote tumor initiation in breast cancer tissue ( $\mathrm{Lu}$ et al., 2014). The EMT program first induces the expression of the surface ligands Thy1 and EphA4, which enable more frequent cell-cell interactions between TAMs and CSCs. Upregulated TAM-CSC contact thus activates the EphA4 receptor on CSCs and its downstream Src and NF- $\mathrm{B}$ pathways (Iliopoulos et al., 2009; Lu et al., 2014). NF- $\kappa$ B activation positively reinforces the secretion of cytokines, including IL-6, IL-8, and GM-CSF, which are crucial for CSC self-renewal and stemness state maintenance (Rinkenbaugh and Baldwin, 2016; Choi et al., 2019). Interestingly, proinflammatory M1 macrophages were also found to play a role in breast CSC formation due to their activation of the STAT3 and NF-кB pathways by $\mathrm{CD} 44^{\text {high }} / \mathrm{CD} 24^{-/ \text {low }}$ or $\mathrm{ALDH}_{1}^{+}$CSCs, while M2 macrophages maintained a higher population of $\mathrm{ALDH}^{+}$cells (Guo et al., 2019). There is a possibility that M1 macrophages, through M2-mediated signaling, modulate CSC formation and regulate tumor initiation. Other signaling pathways, such as PTN/ $\beta$-catenin, Notch 1 and p38-MAPK, are also involved in stimulating CSC self-renewal in lymphoma, lung and ovarian cancers via the preferential secretion of IL-10 and IL-17 by TAMs (Xiang et al., 2015; Wei X. et al., 2019; Yang et al., 2019). Taken together, TAMs, through activating STAT3 and NF- $\mathrm{B}$ signaling cascades and cytokines IL$1 \beta$, IL-6, IL-8, IL-10, and IL-17 and growth factor TGF- $\beta$, play an important role in the self-renewal and chemoresistance of CSCs.

Numerous studies have demonstrated the direct regulation of CSC self-renewal and proliferation by TAMs. CSCs also take advantage of TAM immunosuppressive functions to escape immune surveillance. In HCC, TAMs provide a "safe" environment for CSCs by overexpressing $\operatorname{SIPR} \alpha$, which interacts with CD47 that in turn acts as a "Don't eat me" signal and protects CSCs from being phagocytosed. Recently, CD24, one of the liver CSC markers, was identified to be another "Don't eat me" signal to macrophages by binding to inhibitory receptor sialic-acid-binding Ig-like lectin 10 (Siglec-10) (Lee et al., 2014; Barkal et al., 2019). Liver CSCs may also escape the clearance of macrophages by interacting with their surface Siglec-10 receptor. TAMs also influence T-cell cytotoxic activity by stimulating immune checkpoint molecules such as programmed death-ligand 1 (PD-L1) in cancer cells and $\mathrm{T}$ cell immunoglobulin and mucin domain-containing protein 3 (TIM-3), programmed cell death protein-1 (PD-1) and cytotoxic T-lymphocyte-associated protein-4 (CTLA-4) on the T cell surface, leading to an impaired immune response (Cassetta and Kitamura, 2018; Liu et al., 2018; Xiao et al., 2018). Interestingly, it has been proposed that leukemic CSCs secure their survival by overexpressing TIM3, which promotes MDSCs and subsequent differentiation into TAMs in the leukemic stem cancer niche (Kikushige et al., 2010; Gao et al., 2014; Raggi et al., 2016). The relationship between TIM-3 expression and CSCs has also been shown in melanoma, osteosarcoma, as well as liver, lung, and ovarian cancers (Fourcade et al., 2010; Gao et al., 2012). To protect themselves from being targeted, deterioration in the antigen-presenting ability of TAMs also minimizes macrophage stimulation of T-cell and NK cell cytotoxicity activity (Lewis and Pollard, 2006).

In summary, complicated STAT3/NF- $\kappa \mathrm{B}$ crosstalk is established between CSCs and TAMs in the TME, in which
CSCs attract, re-educate, and put macrophages into their service to support primary tumor growth.

\section{DENDRITIC CELLS}

Dendritic cells are antigen-presenting cells that elicit innate or adaptive immune responses (Ma et al., 2013). Immature DCs capture tumor-derived antigens and present them on their cell surface to immune cells with proper costimulatory molecules, resulting in an antigen-specific immune response and the formation of $\mathrm{T}$ and $\mathrm{B}$ cell memories (Ravindran et al., 2019). Nevertheless, DCs exert antitumor or protumor immune responses in accordance with their distinct morphologies and phenotypes.

A growing number of research studies have demonstrated the importance of CSCs in immune evasion by changing DC phenotypes and impeding their recruitment to the TME. CSCs are responsible for influencing the functional differentiation and activation of DCs, turning DCs to become tolerogenic or limiting them to activate $\mathrm{T}$ cells (Jachetti et al., 2015; Zhong et al., 2019). CD133 ${ }^{+}$CSCs impair the function of DCs by reducing the quantity of activated DCs in colorectal cancer (Szarynska et al., 2018). The EpCAM ${ }^{+}$HCC subtype has stemness properties and induces AFP expression, which hinders DC differentiation, maturation and $\mathrm{T}$ cell proliferation (Yamashita et al., 2009; Pardee et al., 2014). CSCs also produce immunosuppressive cytokines IL-4, IL-10, IL-13, and TGF$\beta$, and express higher levels of coinhibitory molecules such as PD-L1, B7-H3, and IDO1 (Shipitsin et al., 2007; Todaro et al., 2007). These molecules play crucial roles in accumulating immunosuppressive DCs, which hamper the antitumor response by inducing $\mathrm{T}$ cell tolerance and $\mathrm{T}$ reg cell recruitment (Boks et al., 2012; Pardee et al., 2014). TGF- $\beta$ is known for its negative effect on immune response; in terms of DCs, TGF- $\beta$ inhibits DC activation by suppressing the expressions of its costimulatory molecules CD80 and CD86 and MHC class II (Kobie et al., 2003; Fainaru et al., 2007). Defective RIG-I liver CSCs reduce DC population and induce immunotolerance by upregulating TGF$\beta$ signaling (Zhong et al., 2019). Additionally, TGF- $\beta$ promotes Wnt/ $\beta$-catenin activation and thus impairs the recruitment of BATF3 $^{+}$DCs, which is correlated with $\mathrm{CD} 8^{+} \mathrm{T}$ cell infiltration (Spranger et al., 2017). Via $\beta$-catenin activation, TGF- $\beta$ impairs T cell mediated immune surveillance and subsides DC recruitment to the tumor site, consequently incurring HCC immune escape and resistance to anti-PD1 treatment (Ruiz de Galarreta et al., 2019). Moreover, TGF- $\beta$ encourages the development of PDL1-expressing immunosuppressive DCs, resulting in weakened $\mathrm{CD}^{+} \mathrm{T}$ cell activity in a metastatic ovarian cancer model (Cubillos-Ruiz et al., 2010; Krempski et al., 2011).

In the TME, cancer and stromal cells also express C-XC motif chemokine receptor 4 (CXCR4) and produce its ligand $\mathrm{C}-\mathrm{X}-\mathrm{C}$ motif ligand 12 (CXCL12) to sustain CSC selfrenewal and to recruit regulatory DCs. These DCs produce CXCL12 themselves in an autocrine manner and employ a feedforward mechanism for maintaining CSC stemness (Sultan et al., 2017). Similar to TAM-mediated escape from phagocytic killing, 
overexpressed CD47 on CSC surface elicits "Don't eat me" signal by binding to signal regulatory protein alpha (SIPR $\alpha)$, which acts in phagocytosis signaling pathway of DCs (Liu et al., 2017). Although recent findings showed CSCs hijack immune responses by impairing DC functions and recruiting immunosuppressive DC subsets, more investigations are necessary to shed light on the interactions between these two cell types, especially on how DCs alternately regulate CSC stemness properties.

\section{MYELOID-DERIVED SUPPRESSOR CELLS}

Myeloid-derived suppressor cells are a heterogeneous subset of myeloid-originated progenitor cells. In humans, these cells are defined by $\mathrm{CD} 11 \mathrm{~b}^{+} \mathrm{CD} 14^{-} \mathrm{CD} 33^{+}$, while in mice, they are characterized by CD11b ${ }^{+} \mathrm{Gr}^{+}$(Kusmartsev et al., 2004; Nagaraj and Gabrilovich, 2010). MDSCs have been used as a prognostic indicator for patients' responsiveness to immunotherapy and their survival, as they account for the majority of cells that promote an immunosuppressive environment in the TME (Ai et al., 2018). MSDCs can be classified into two main populations according to their different nuclear morphologies: monocyticMDSC (mMDSC) and granulocytic-MDSC (gMDSC). They are endowed with different immunosuppressive molecules: mMDSC contains both arginase- 1 and iNOS, while g-MDSC contains high levels of arginase-1; therefore, are suggested to exert distinct spatiotemporal regulations on tumor plasticity (Ouzounova et al., 2017). Both mMDSC-derived iNOS and NO, and gMDSCinduced ROS and arginase-1, can lead to TCR peroxynitration and $\mathrm{T}$ cell apoptosis (Nagaraj and Gabrilovich, 2010). In addition, MDSCs produce the immunosuppressive cytokines IL-10 and TGF- $\beta$ as well as PD-L1, which together suppress T cell activity and recruit Tregs (Ostrand-Rosenberg, 2010). They also convey their immunosuppressive functions to macrophages, NK cells and DCs via crosstalk.

Myeloid-derived suppressor cell accumulation in the TME is facilitated by the secretion of cytokines, including IL-1 $\beta$, IL-6, G-CSF, M-CSF, GM-CSF, macrophage MIF, and TGF$1 \beta$, and chemokines CCL1, CCL2, CCL5, CCL22, CXCL2, CXCL5, and CXCL12. The quantity of infiltrating MDSCs is positively associated with CSCs in cancer patients. In a synergistic mammary tumor model, CSCs enhance G-CSF, which is responsible for recruiting MDSCs to the tumor site (Welte et al., 2016). Activation of IL-6/STAT3 signaling has been reported to promote the differentiation of monocytes to MDSCs (Panni et al., 2014). Reciprocally, MDSCs promote the stemness and mesenchymal properties of cancer cells through NOTCH/STAT3 signaling, forming a positive feedback loop with crosstalk between MDSCs and CSCs (Welte et al., 2016; Ouzounova et al., 2017). Via secretion of prometastatic molecules such as MMP9 and chitinase 3-like 1 (CHI3L1), recruited MDSCs enhance stem cell features to promote tumorigenesis and metastasis in triple-negative breast cancer (Kumar et al., 2018). MDSCs also enrich breast cancer cells with stem-like properties by activating IL-6/STAT3 and NO/NOTCH signaling pathways with NO, leading to suppression of $\mathrm{T}$ cell activation (Peng et al., 2016).
Intriguingly, MDSCs play an additional important role beyond just IL-6-induced transient STAT3 activation. Cell-derived IL6 further increases IL-6 and IL6R $\alpha$ in MDSCs, thus allowing MDSCs to prolong STAT3 signaling activation and maintain STAT3 phosphorylation. IL-6-derived MDSC regulation of CSC expansion and immunosuppressive activity is present in both breast and liver cancers (Peng et al., 2016; Xu et al., 2017).

In addition, MDSCs influence cancer stemness via modulation of RNA interference as well as epigenetic regulation. MDSCs trigger miR-101 expression in ovarian cancer, thus inhibit the corepressor $\mathrm{CtBP} 2$ from repressing the transcription of stem cell core genes, leading to an upregulation of stemness markers and tumor growth (Cui et al., 2013). In a co-culture setup, gMDSCs are found to enhance expression of stemness genes and CSC phenotypes of multiple myeloma cell lines through piRNA-823 and subsequent activation of DNA methyltransferases DNMT3B (Ai et al., 2019). MDSCs also increase stem-like properties in ovarian CSCs by upregulating prostaglandin E2 (PGE2) and PDL1 expressions (Komura et al., 2020). Under hypoxic conditions where liver CSCs are enriched, MDSCs migrate to the tumor site through ENTPD2/CD39 L1 signaling. These MDSCs further promote HCC progression and reduce the efficacy of PD1 therapy (Chiu et al., 2017). Interestingly, depletion of MDSCs leads to sensitization of HCC cells to 5-FU (Xu et al., 2017). Reduction of MDSCs by Listeria bacteria or herpes simplex virus expressing 15-PGDH can attenuate tumor growth and metastasis in breast cancer (Walker et al., 2011; Chandra et al., 2013). All of these findings emphasize the role of MDSCs in reshaping stemness in breast, ovarian and liver cancers and demonstrate the possibility of targeting MDSCs along with CSC eradication in future immunotherapy.

\section{REGULATORY T CELLS}

Regulatory $\mathrm{T}$ cells (Tregs) are a group of $\mathrm{CD}^{+} \mathrm{T}$ cells with tumor-promoting effects, usually defined by the Foxp $3^{+} \mathrm{CD} 25^{+} \mathrm{CD} 4{ }^{+} \mathrm{T}$ cell subpopulation (Sakaguchi et al., 2010). Tregs abolish host defense mechanisms and exert their functions by inhibiting effector T cells and other immune cells by secreting immunosuppressive cytokines such as IL-10, IL-35, and TGF- $\beta$.

A positive correlation has been observed between the presence of CSCs and Tregs in cancers, suggesting possible crosstalk between these cell populations in promoting an immunosuppressive milieu (Yu et al., 2012; Napoletano et al., 2016; Solis-Castillo et al., 2020). In glioblastoma, CSCs induce Treg cell infiltration mediated by the costimulatory molecule PD-L1, soluble Galectin-3, and TGF- $\beta$ secretion (Wei et al., 2010, 2011), whereas ABCB5 ${ }^{+}$melanoma cells induce Treg cell infiltration via a B7-2-dependent mechanism (Schatton et al., 2010). Chemokines such as CC17, CCL22, and CCL28 are also produced by various cancers to attract Foxp $3^{+}$Treg cells.

CSCs have been suggested to affect the Th17/Treg balance by altering the production of cytokines such as IL-6 and IL-8 and chemokine CCL5 in the TME (Yu et al., 2012). Treg/Th17 homeostasis has been implicated in its dual effect 
on the promotion or suppression of cancer (Maniati et al., 2010; Marshall et al., 2016; Knochelmann et al., 2018). A study on Treg and Th17 cells demonstrated STAT3 was a pivotal transcription factor in Th17 differentiation and Treg inhibition, whereas STAT3 is significantly activated in gastric CSCs (Wei et al., 2008; Rezalotfi et al., 2019). Therefore, STAT3 may act as a key factor in modulating CSC stemness and expansion as well as Th17/Treg homeostasis. Yang et al. (2011) demonstrated that IL-17 Tregs stimulate the development of colorectal cancerrelated stemness markers, including CD44, CD133, CD166, EpCAM, and ALDH, in bone marrow-derived mononuclear cells and drive cells to become CSCs, indicating the ability of Tregs to induce CSC development. In addition, Tregs release PGE2, which promotes colorectal CSC expansion and metastasis in a mouse model through NF- $\mathrm{kB}$ activation (Wang et al., 2015). Indirect interactions between Tregs and CSCs act on the regulation of angiogenesis, TGF- $\beta$ signaling and macrophage-associated EMT (Mima et al., 2012; Yu et al., 2012; Liu et al., 2021). Under hypoxic conditions, Tregs, which are an important source of VEGF expression, release TGF- $\beta$ and indirectly regulate CSC expansion by mediating angiogenesis (Facciabene et al., 2011). Additionally, VEGF signaling was found to promote CSC stemness and expansion in melanoma (Beck et al., 2011). Depletion of Tregs lowers VEGF-A and decreases vascularization in tumors. Blockade of VEGFR2 leads to a shrunken CSC population and impaired self-renewal. Similar results have been demonstrated in brain tumors, where the vascular niche directly correlates with CSC generation (Treps et al., 2017). Blockade of angiogenesis signaling significantly inhibits brain CSCs due to reduced blood vasculature in tumors. In line with clinical data, metastatic renal cancer patients who receive antiangiogenic therapy have an overall survival strongly correlated with the reduction in Treg numbers (Brodaczewska et al., 2018). Additionally, the angiogenetic situation is aggravated by TAM preferential secretion of VEGF and IL-8, doubling the effect on promoting CSC proliferation (Werno et al., 2010). Apart from angiogenesis, Tregs also promote CSC expansion by TAMmediated EMT induction via the expression of CTLA-4, IL-10, and TGF- $\beta$ (Yu et al., 2012).

Overall, CSCs induce Treg infiltration via costimulatory molecules and STAT3 signaling in the TME, while Tregs alternately regulate CSC proliferation and expansion directly via secretion of IL-17 and PGE2 or indirectly through TGF$\beta$-mediated angiogenesis and EMT.

\section{NATURAL KILLER CELLS}

Natural killer cells represent a population of cytotoxic lymphocytes with an innate immune response and are responsible for eradicating tumor cells. High cytotoxic activity of NK cells is correlated with a lowered cancer risk (Imai et al., 2000). Approximately $95 \%$ of peripheral blood NK cells are $\mathrm{CD} 56^{\operatorname{dim}} \mathrm{CD} 16^{+}$, which exert strong cytotoxic activity.

Beside antibody-dependent cellular cytotoxicity (ADCC) via Fc receptors bound to target cells, NK cells recognize target cells in cell-cell interactions through a variety of activating and inhibitory receptors. Activating receptors, including NKG2C, NKG2D, and NCR, as well as inhibitory receptors, such as Ly49, bind to MHC or HLA class I molecules and cellular stress ligands, leading to the NK cell response (Zhang et al., 2020a). In response to exposure to cancer cells, preferential NK killing of CSCs has been demonstrated in oral squamous carcinoma, human colon carcinoma, melanoma and glioblastoma (Castriconi et al., 2009; Pietra et al., 2009; Tseng et al., 2010; Tallerico et al., 2013; Pan et al., 2015). Specific killing of CSCs with the stem cell markers $\mathrm{CD} 24^{+}, \mathrm{CD}_{133^{+}}$, and $\mathrm{ALDH}^{+}$confirms the role of NK cells in effectively targeting and eradicating CSCs. This selective recognition of CSCs has been proposed to be mediated through NKG2D-, DNAM-1- and NKp30-activating receptors (Tallerico et al., 2016). In line with these findings, different types of CSCs express or overexpress the corresponding ligands of those activating receptors with low expression of MHC class I on the surface, leading to effective NK cytotoxicity activity.

However, the preferential tumorigenic capability of CSCs in NOD/SCID mice suggests that there are underlying immunosuppressive mechanisms for CSCs to dodge from NK cell specific killing (Al-Hajj et al., 2003; Tsuchiya and Shiota, 2021). It has been reported that CSCs escape NK-mediated cytotoxicity via various mechanisms by tuning NK receptors. In lung cancer, tumor-derived mesenchymal stem cells (MSCs) alter the NK cell phenotype by downregulating activating receptor expression and inhibiting interferon gamma (IFN- $\gamma$ ) secretion, whereas abortion of PGE2 and restoration of IL-6 activity reverse the tumor-derived MSC-mediated immunosuppression activities (Galland et al., 2017). $\mathrm{CD} 34^{+} \mathrm{CD} 38^{-}$leukemic stem cells were shown to be resistant to allogenic NK-mediated killing (She et al., 2012). Breast $\mathrm{ALDH}^{+}$CSCs escape NK cells by reducing the expression of NKG2D ligands MICA and MICB through miR20a modulation (Wang et al., 2014). Downregulation of MICA/B expression supports CSC resistance to NK cell cytotoxicity and increases their metastatic capacity in vivo. Recent research also revealed the dual immunoinhibitory role of PCNA in upregulating the stemness of pancreatic and colon $\mathrm{CD} 44^{+} \mathrm{CD} 133^{+}$CSCs, as well as participating in immune evasion from NK cytotoxicity by engaging with the inhibitory receptor NKp44 (Malaer and Mathew, 2020). Blockade of the PCNA-NKp44 interaction changes IFN- $\gamma$ secretion and NK cytotoxicity, suggesting a potential immunotherapeutic target for NK cell-mediated attack. The interaction of NK cell coinhibitory receptors, such as PD-1, with their ligands on tumor cells, also suppresses NK cell-mediated glioma CSC eradication (Huang et al., 2015).

As most NK cell-mediated immune responses occur in tumor cells with low levels of MHC-I, melanoma cancer cells may escape NK cells by upregulating MHC-I on their surface. Interestingly, Huergo-Zapico et al. (2018) suggested that NK cells may release tumor necrosis factor-alpha (TNF- $\alpha$ ) and IFN$\gamma$ and induce melanoma cells to undergo EMT, pushing them toward invasive phenotypes. EMT induction endows melanoma cells with upregulated stemness markers and enhances their invasive capability. Moreover, EMT favors immune escape by suppressing activating receptors or HLA class-I (Chen et al., 2015). In contrast, some reports have demonstrated that EMT 
induction promotes NKG2D-L expression on colorectal cells and upregulates NK cell-mediated immunosurveillance in lung cancer (Lopez-Soto et al., 2013; Chockley et al., 2018). This finding suggests that the disparity of the EMT-derived NK cell immune response is dependent on the cancer type.

In summary, NK-mediated killing plays an important role in immune response in diminishing CSCs through the assistance of various activating and inhibitory receptors. Nevertheless, CSCs may escape specific targeting by modulating the expression of these receptors. A novel study also pointed out that NK cells may clash with their classical cytotoxic activity by promoting EMT in CSCs, dependent on the cancer type (Huergo-Zapico et al., 2018).

\section{TUMOR-INFILTRATING LYMPHOCYTES}

Tumor-infiltrating lymphocytes represent all lymphocytic cell populations, including $\mathrm{CD}^{+}, \mathrm{CD}^{+}$, and a small portion of $\mathrm{B}$ and NK cells that infiltrate the TME. TILs have been observed in the majority of solid tumors, such as breast, liver and lung cancers (Biller and Dow, 2007). These cells exert diverse effects on the immune response toward the tumor and are correlated with tumor aggressiveness, metastasis, treatment response rate and tumor recurrence. Subsequent to antigen stimulation by APCs, activated helper $\left(\mathrm{CD}^{+}\right) \mathrm{T}$ cells (Th) support the antitumor immune response by further activating cytotoxic $\left(\mathrm{CD}^{+}\right) \mathrm{T}$ cells (CTLs) and recruiting innate immune cells. Th cells stimulate CTLs by IL-2 secretion and cell-cell interactions through costimulatory molecules, including MHC-II, CD27 and CD134 (Giuntoli et al., 2002). Cancer cells, by producing CCL18, recruit Tregs that promote tumor formation and impact other immune cells (Paluskievicz et al., 2019). Bone marrow-derived MSCs have been reported to recruit and maintain Tregs via TGF$\beta$ secretion, leading to a negative regulation on $\mathrm{T}$ cell proliferation (Di Ianni et al., 2008; Papaccio et al., 2017). Moreover, tumorderived TGF- $\beta$, TNF- $\alpha$, and IFN- $\gamma$ induce the differentiation of IL-17 ${ }^{h i}$ Th17 cells, which supports angiogenesis and enhances protumor transcription factors (Maniati et al., 2010).

The presence of TILs frequently represents a good prognosis for cancer patients (Fridman et al., 2011; Dieci et al., 2014; Idos et al., 2020). Tumor-specific $\mathrm{CD}^{+} \mathrm{T}$ cells induced by CSCs in vitro demonstrated an effective antitumor response, including inhibiting tumor growth and metastasis with prolonged survival in pancreatic and lung cancer mouse models (Visvader and Lindeman, 2008; Luo et al., 2014). Nevertheless, CSCs are capable of attenuating the action of these cells directly by altering their PD-L1 expression. Elevated stromal TILs and their PD-L1 expression in inflammatory breast cancer and lung adenocarcinoma have been reported to be significantly associated with CSC markers (Mansour et al., 2020; Zhang et al., 2020b). By analyzing PD-L1 expression in a large cohort of HCC patients, Kurebayashi et al. (2018) and others showed that PD-L1 expression in tumor infiltrates is associated with the progenitor subtype of HCC, marked by CK19 and SALL4 expression (Calderaro et al., 2016). High expression levels of PD-L1 are also observed in $\mathrm{CD} 133^{+} \mathrm{CD} 44^{+}$colorectal CSCs and CSCenriched tumor spheres. Hsu et al. (2018) suggested that PD-L1 enrichment in CSCs is mediated by $\beta$-catenin/STT3 signaling through glycosylation modulation and PD-L1 stabilization. Based on the clinical correlation between IL-6 and PD-L1 in HCC patient samples, Chan et al. (2019) showed that IL-6 activated JAK1 signaling cascade-induced N-glycosylation and the stabilization of PD-L1. Notch3/mTOR pathway activation is also reported to mediate $\mathrm{PD}-\mathrm{L} 1$ overexpression on breast CSCs (Mansour et al., 2020). Altered PD-L1 expression, in turn, facilitates colorectal CSC self-renewal with upregulated stemness genes and promotes CSC expansion by activating HMGA1-dependent signaling pathways (Wei F. et al., 2019). PI3K/Akt pathway activation has also been reported to participate in PD-L1-derived promotion of stemness in CSCs (Almozyan et al., 2017).

In addition, interaction with nonlytic $\mathrm{CD}^{+} \mathrm{T}$ cells leads to CSC expansion by cell-cell contact in primary breast cancer cell cultures (Stein et al., 2019). The induction of stemness properties in CSCs was confirmed by enhanced tumorigenesis in immunodeficient mice, and the resulting tumors were endowed with a higher cell density and an increased proliferation rate, as well as an elevated chance of lymphoid metastasis. Taken together, these findings showed that the ineffective cytotoxic activity of tumor infiltrates not only fails to eradicate malignancy but also conversely facilitates immune evasion by promoting CSC stemness, proliferation and tumorigenesis of cancer cells. The interaction between various immune cells and CSCs was summarized in Figure 1.

\section{DEVELOPMENT OF CSC-TARGETED IMMUNOTHERAPY}

Immune checkpoint CTLA-4 and PD-1 inhibitors revolutionized cancer research in the last decade and brought immunology back to the spotlight in therapeutic development. As immunotherapy relies on the immune system to recognize and attack tumor cells, it takes into account not only the tumor cells but also the TME as a therapeutic target to induce a powerful antitumor response. It is clear that CSCs and differentiated tumor cells exhibit distinct gene expression and functions in the tumor bulk, and therefore immunological targeting of the tumor bulk will be biased toward more differentiated tumor cells that express differentiated antigens (Pan et al., 2015). Effective targeting of CSCs may require highly specific identification of the CSC population. Currently, immunological targets of CSCs in therapeutic development have now been focused on three major approaches: CSC-associated antigens, phenotypes and niches.

The innate immune response, including NK and DC cells, exhibits cytotoxic activities toward tumor cells when they are exposed to foreign antigens in the normal immune system. The innate effector and antigen-presenting properties of NK and DC cells empower them to be suitable candidates for immunotherapy. Furthermore, several studies demonstrated that chemotherapy or radiation therapy increased MICA and MICB expression on CSCs, accompanied with CSC expansion (Ames et al., 2015b). This highlights the prospective use of NK cell therapy in combination with traditional therapies in 


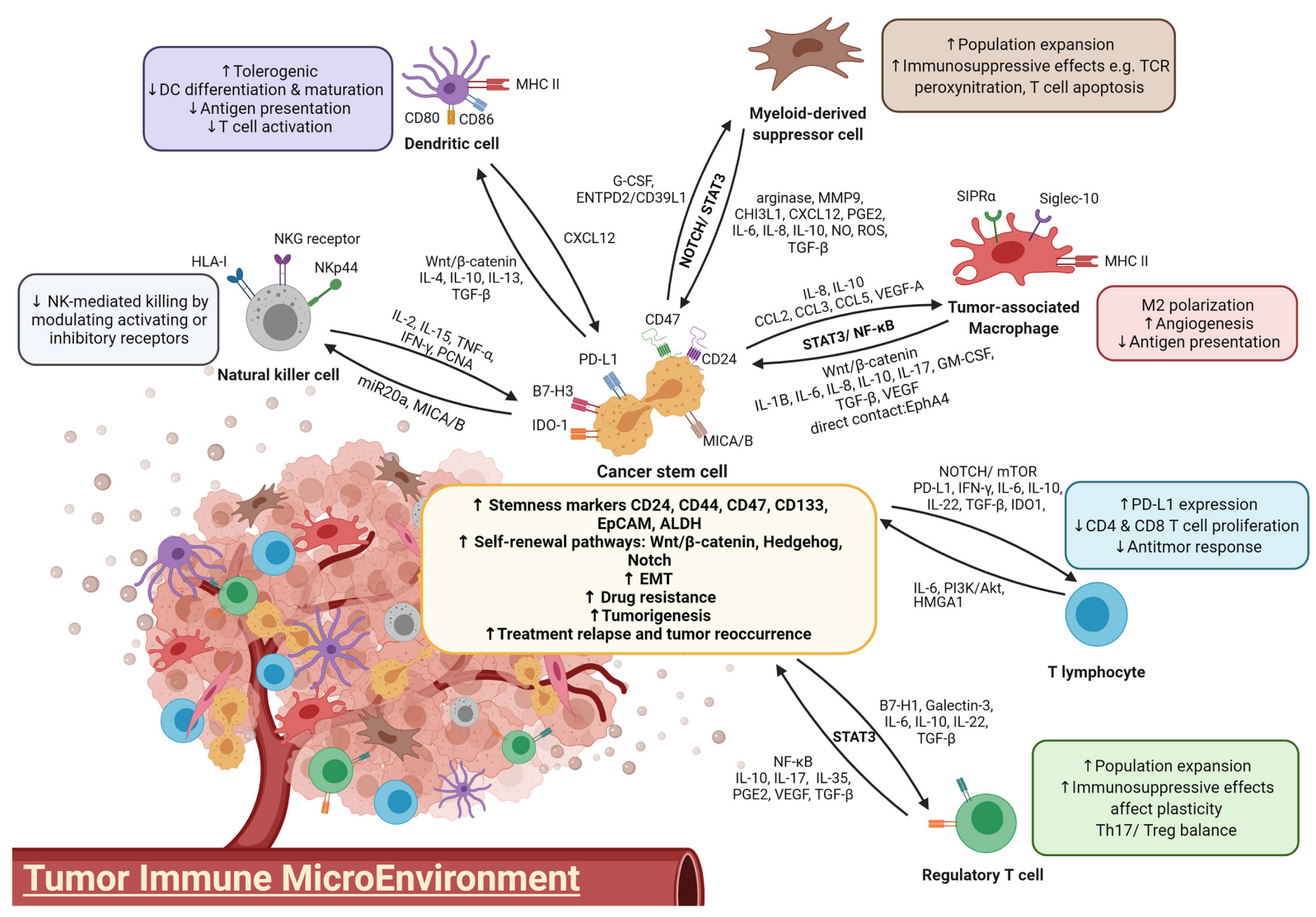

FIGURE 1 | A diagram illustrating the crosstalk between immune cells and CSCs.

eradicating CSCs. Currently, several clinical trials using NK cells infusion (NCT04162158 and NCT03592706) or in combination therapies (NCT03319459) to treat advanced solid tumors are ongoing. Adoptive NK cell therapy aims to strengthen and reinforce the antitumor functions of NK cells from autologous and allogeneic sources (Wang et al., 2021). After exposure to cytokines such as IL-2 and IL-5, NK cells prolong their activation and exhibit increased cytotoxicity. IL-2- and IL-15-activated NK cells have been shown to be able to eradicate human breast, colon, glioblastoma and melanoma CSCs (Castriconi et al., 2009; Ames et al., 2015a; Yin et al., 2016). A phase I clinical trial using allogeneic NK cells to target CSCs in advanced biliary tract cancer was conducted (NCT03358849). However, the administration of the activating cytokine IL-2 may also lead to the expansion of other immunosuppressive immune cells, including Treg cells (Koreth et al., 2016). In addition, to consistently activate NK cells, the trafficking and maintenance of engineered cytokines such as mbIL-15 and mbIL-21 will also need to be modified during the development of NK cell therapy (Pittari et al., 2015).

Sipuleucel-T is the first FDA-approved DC vaccine against advanced prostate cancer, ensuring DCs as a promising therapeutic strategy in immunotherapy (Cheever and Higano, 2011). DC vaccination has been confirmed to have effective immunologic activities in several preclinical studies. Stimulating
DCs with CSC-designated antigens is believed to facilitate CSC eradication with high specificity and effectively resolve CSCmediated tumor relapse and metastasis (Pang et al., 2019). However, clinical trials reported only a 10 to $15 \%$ response to DC vaccination by several cancer types (Anguille et al., 2014). One of the problems leading to low efficacy is the immunosuppressive effect from the upregulation of immune checkpoints (Shi et al., 2018). Recently, CSC-targeted DC vaccines have been reported to enhance the elimination of melanoma CSCs in a mouse tumor model with a combination of PD-L1 and CTLA-4 blockades, with an enhanced $\mathrm{CD}^{+} \mathrm{T}$ cell response, increased IFN- $\gamma$ and inhibited TGF- $\beta$ expression (Zheng et al., 2018). This finding demonstrates the potential of CSC-based DC vaccines in combinational therapy.

The FDA has approved the use of chimeric antigen receptor (CAR)-T cell therapies targeting CD19 in treating lymphoma since 2017 (FDA, 2017). Increasing numbers of preclinical studies have demonstrated effective immunological control of CAR-T cells in inhibiting cancer growth and prolonging host survival (Chong et al., 2017; Foster et al., 2017; Heczey et al., 2017; Kloss et al., 2018; Zhang et al., 2019). As CAR-T therapy has been in use with a high success rate in treating lymphoma and leukemia, it has also been proposed for targeting CSCs. CSCrelated markers such as CD133, EpCAM, and CD90 have been identified as targeted antigens for CAR-T cells (Guo et al., 2018). 
TABLE 1 | Therapeutic strategies targeting the CSC niche and their development progress.

Trial description
CSC-associated molecules
NK cell therapy

NK cell therapy

Drug name

Molecular targets

Mechanism of action

Phase of drug development

FAKE-NK100
SMT-NK

CAR-T cell therapy CARTEPC

Pathways

iL-6/JAK/STAT

IL-8

$N F-k B$

Acalabrutinib

Ibudilast (MN-166)

LCL-161

AZD-1480

Celecoxib (FDA approved)

Pyrimethamine (FDA approved)

Tocilizumab

Siltuximab

Reparixin

HLA

EpCAM T cell cytotoxicity

CD133

JAK $1 / 2$

STAT3

STAT3

IL-6

IL-6

CXCR1

BTK

TLR4

C-IAP

TGF- $\beta$

.

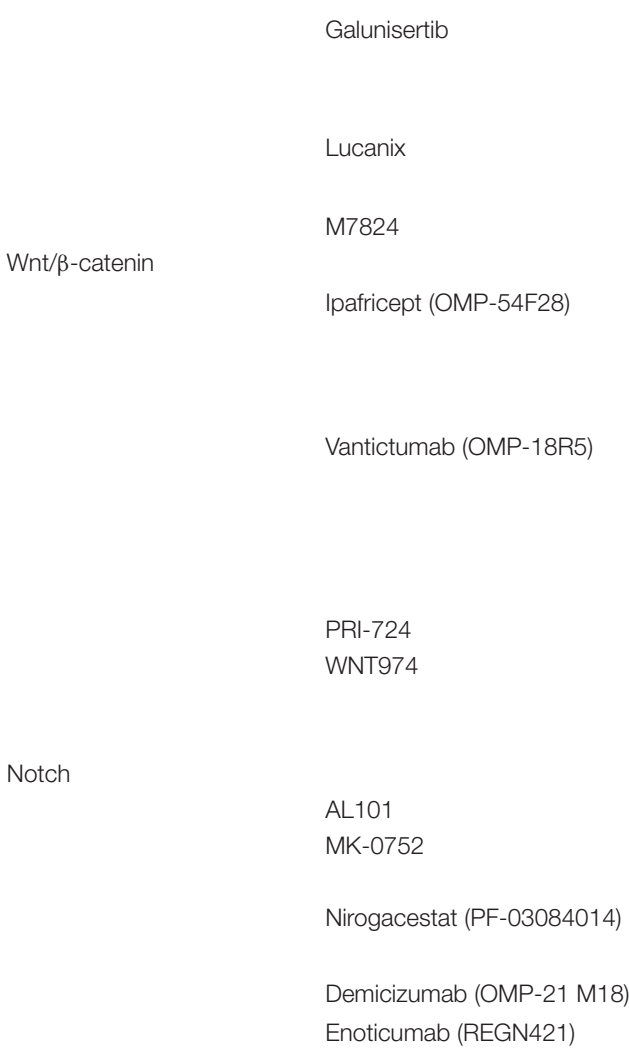

Fresolimumab

TGF- $\beta 1 / 2 / 3$

TGF- $\beta$ R 1

TGF- $\beta 2$

TGF- $\beta / P D-L 1$

FZD receptor

FZD receptor

$\mathrm{CBP} / \beta$-catenin Antagonist PORCN

$\gamma$-Secretase

$\gamma$-Secretase

$\gamma$-Secretase

DLL4

DLL4

Inhibition of JAK1/2
NK cell killing

Monoclonal antibody against FZD receptors

Inhibition of PORCN

Inhibition of STAT3

Inhibition of STAT3

IL-6R monoclonal antibody

IL-6R monoclonal antibody

Inhibition of CXCR1

Inhibition of BTK

TLR4 antagonist

Inhibition of C-IAP

Neutralizing antibody

Inhibition of TGF- $\beta$ R1

Antisense oligonucleotide

Ligand trap

I/IIII

I

I

I/II

I/II

I

III

I/II

II

॥

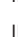

II

II

III

II

$\|$

/

I/II

II

|/II

II

II

II

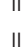

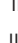

III

III

I

I

I

I

I

II

II

I/II

I

Inhibition of S3 cleavage

Inhibition of S3 cleavage

Inhibition of S3 cleavage

Blockade of DLL4

Monoclonal antibody against

DLL4
NCT04162158;

NCT03592706;

NCT03319459;

NCT03358849

NCT03013712

NCT02541370

NCT01112397

NCT00087256

NCT01066663

NCT03999749

NCT03315026

NCT01861054;

NCT02370238

NCT04008706

NCT03782415

NCT01617668;

NCT02649673

NCT01472731; NCT02581787

NCT02688712;

NCT02538471;

NCT01246986

NCT01058785;

NCT00676507

NCT04066491

NCT01608867; NCT02050178; NCT02092363;

NCT02069145

NCT01957007;

NCT01973309;

NCT01345201;

NCT02005315

NCT01302405

NCT02649530;

NCT02278133;

NCT01351103

NCT03691207

NCT00106145;

NCT01098344

NCT02109445;

NCT02299635

NCT02259582

NCT00871559

VEGF 
TABLE 1 | Continued

\begin{tabular}{|c|c|c|c|c|c|}
\hline Trial description & Drug name & Molecular targets & Mechanism of action & $\begin{array}{l}\text { Phase of drug } \\
\text { development }\end{array}$ & References \\
\hline & Bevacizumab (FDA approved) & VEGFR & $\begin{array}{l}\text { Inhibition of VEGF binding to } \\
\text { receptor }\end{array}$ & $\|$ & NCT02226289; \\
\hline & & & & III & NCT02420821; \\
\hline & & & & III & NCT03434379 \\
\hline \multicolumn{6}{|l|}{ Immune cells } \\
\hline \multirow[t]{13}{*}{ TAMs } & Zoledronate acid & Mevalonate pathway & Elimination & $\mid / I I$ & NCT00588913; \\
\hline & & & & III & NCT02622607 \\
\hline & BMS-813160 & $\mathrm{CCR} 2 / 5$ & $\begin{array}{l}\text { Inhibition of macrophage } \\
\text { recruitment }\end{array}$ & $\|$ & NCT04123379; \\
\hline & & & & $\mid / I I$ & NCT03767582; \\
\hline & & & & $|/| \mid$ & NCT03496662; \\
\hline & & & & $\|$ & NCT02996110 \\
\hline & BL-8040 & CXCR4 & Antagonist & $\|$ & NCT02826486; \\
\hline & & & & $\|$ & NCT02907099 \\
\hline & Pexidartinib & CSF-1R & Inhibition of CSF-1R & 1 & NCT02777710 \\
\hline & AMG820 & CSF-1R & $\begin{array}{l}\text { Monoclonal antibody against } \\
\text { CSF-1R }\end{array}$ & $|/| \mid$ & NCT02713529 \\
\hline & ALX148 & $\mathrm{CD} 47 / \mathrm{SIRP} \alpha$ & Blockade of CD47 & 1 & NCT03013218 \\
\hline & IBI322 & $\mathrm{CD} 47 / \mathrm{SIRP} \alpha$ & $\begin{array}{l}\text { CD47/PD-L1 bispecific } \\
\text { antibody }\end{array}$ & 1 & NCT04328831 \\
\hline & Hu5F9-G4 & $\mathrm{CD} 47 / \mathrm{SIRP} \alpha$ & $\begin{array}{l}\text { Monoclonal antibody against } \\
\text { CD47 }\end{array}$ & 1 & NCT02216409 \\
\hline \multirow[t]{3}{*}{ MDSCs } & INCB001158 & Arginase & Inhibition of arginase & $|/| I$ & NCT02903914 \\
\hline & Decitabine & Arginase & Differentiation & 1 & NCT00030615 \\
\hline & Entinostat & Arginase & Elimination & 1 & NCT02453620 \\
\hline \multirow[t]{4}{*}{ NK cells } & Lirilumab & $\mathrm{KIR}$ & $\begin{array}{l}\text { Blockade of inhibitory signal of } \\
\text { NK cells }\end{array}$ & $\mid / I I$ & NCT03532451; \\
\hline & & & & & NCT01714739 \\
\hline & Monalizumab (IPH2201) & NKG2A & Inhibition of immune checkpoint & $\mid / I I$ & NCT03822351; \\
\hline & & & & & NCT03833440 \\
\hline Tregs & Ontak (Denileukin diftitox) & CD25 & Induction of apoptosis & $\|$ & NCT00726037 \\
\hline
\end{tabular}

Zhu et al. (2015) successfully eliminated CD133 ${ }^{+}$CSCs derived from glioblastoma patients; however, T cell aging marker CD57 was induced as a side effect. Recently, a phase I clinical trial (NCT02541370) using autologous CD133-targeted CAR-T cells to treat 23 patients with advanced $\mathrm{CD}_{133^{+}}$tumors resulted in a benefit of 5-month median progression-free survival, with controllable toxicity (Wang et al., 2018b). Zhang et al. (2019) also reported that adoptive transfer of EpCAM-targeted CAR-T cells significantly reduced tumor growth in a xenograft model without safety issues. An EpCAM-targeted CAR-T cell clinical trial (NCT03013712) is in progress for targeting $\mathrm{EpCAM}^{+}$ cancers. To minimize the toxicity to normal cells, targeting these CSC markers can be coupled with an inhibitory receptor with specificity for normal tissue antigens.

Yet, more investigations are necessary to overcome the challenges of using CAR-T cells to eliminate CSCs. One of the limitations in developing CAR-T cells targeting CSCs is the diverse treatment response due to the distinct CSCs plasticity and heterogenicity in patients (Alhabbab, 2020). Common immunotherapy hurdles, including acquired resistance as well as upregulation of immune checkpoints are also observed in T cell immunotherapies. Miao et al. (2019) demonstrated that TGF- $\beta$-enriched CSCs dampened the cytotoxicity of adoptive T cells by promoting the exhaustion state through CD80-CTLA4 interaction in squamous cell carcinoma. The findings of adaptive immune resistance raised from CSCs against immunotherapy echoes with the previously proposed immunosuppressing feature of CSC, and furthermore emphases CSC as the root of tumor relapse (Tsuchiya and Shiota, 2021).

In addition to direct targeting CSC phenotype and markers, researchers have also targeted the CSC niche, which contributes to CSC self-renewal and immune escape. This includes CSCassociated pathways, cytokines and immune cells (Table 1). As mentioned above, CSCs maintain their self-renewal by generating a positive feedback loop with immunosuppressive cells such as TAMs through JAK/STAT3, Wnt/ $\beta$-catenin, and NF- $\kappa \mathrm{B}$ crosstalk activation, with the expression of inhibitory cytokines such as IL-6, IL- 8 , and TGF- $\beta$. Wnt/ $\beta$-catenin-targeted therapies such as anti-FZD receptors monoclonal antibody (Vantictumab), $\beta$-catenin inhibitors PRI-724, as well as smallmolecule porcupine inhibitor WNT974 are currently in clinical trials. Wnt-targeted treatments are proposed to be implemented as combinational therapies with immune checkpoint inhibitors such as nivolumab and ipilimumab or tyrosine kinase inhibitors, in order to pinpoint the immune evasive ability of CSCs in Wntdriven cancers (Katoh, 2017). Blockade of IL-6 was previously 
proven to affect non-small cell lung cancer tumorigenesis and the proliferation of H460 lung CSCs (Yi et al., 2012). The IL-6 receptor monoclonal antibody tocilizumab has been reported to suppress the premetastatic ability of breast CSCs and potentiate the cytotoxicity of cisplatin against triple-negative breast cancer (Alraouji et al., 2020). The drug has been approved by the FDA for treating rheumatoid arthritis and is now under phase II study for curing advanced melanoma in combination with the immune checkpoint inhibitors nivolumab and ipilimumab (NCT03999749). Blockade of the IL-8 receptor CXCR1 using small molecule Reparixin successfully attenuated the CSC population and induced massive apoptosis in a breast cancer cell line. The result of phase I clinical trial showed that Reparixin is safe and well tolerated, in combination of paclitaxel (Schott et al., 2017). Phase II study of this drug showed a $\geq 20 \%$ reduction in CSC markers $\mathrm{ALDH}^{+}$and $\mathrm{CD} 24^{-} / \mathrm{CD} 44^{+}$in HER-2-negative breast patients with no serious adverse reactions (Goldstein et al., 2020). Due to the limited number of CSC in primary breast cancer, another clinical trial (NCT02370238) with alternative evaluation endpoint, for example, measurement of metastasis, has been set for assessing the effectiveness of reparixin on CSC eradication (Ruffini, 2019).

The roles of angiogenesis in supporting immunosuppressive TME and self-renewal of CSCs have been extensively studied, thus the combination use with VEGF inhibitor provides a novel direction for immunotherapy. A phase III clinical trial (NCT03434379) of bevacizumab with PD-L1 inhibitor atezolizumab showed a superior outcome in overall and progression-free survival than sorafenib in advanced HCC cases (Finn et al., 2020). Due to this encouraging result, FDA approved the combined use of bevacizumab and atezolizumab as the firstline treatment for unresectable HCC patients (Yang et al., 2020). A recent report on targeting aberrant mRNA modification in leukemia has highlighted another potential therapeutic approach to suppress fat mass and obesity-associated protein (FTO), an RNA N6-methyladenosine (m6A) demethylase (Su et al., 2020). M6A RNA modification has been implicated in self-renewal and tumorigenesis in various cancers, thus is proposed to be a novel therapeutic target against CSCs (Ma and Ji, 2020). Using small molecule inhibitors CS1 and CS2, inhibition of FTO attenuates self-renewal ability of leukemic stem cells via reducing MYC and CEBPA expressions. Targeting FTO also suppresses the immune checkpoint gene LILRB4, and thus sensitizes the cancer cells to T cell cytotoxicity (Su et al., 2020). Thus, the combination of FTO inhibitors and hypomethylating agents (HMA) is recommended for future clinical trials, in order to overcome the adaptive immune resistance induced by HMA treatment in leukemia patients with high FTO.

Direct targeting of immunosuppressive cells such as TAMs with zoledronic acid successfully inhibited the growth of cervical

\section{REFERENCES}

Ai, L., Mu, S., Sun, C., Fan, F., Yan, H., Qin, Y., et al. (2019). Myeloid-derived suppressor cells endow stem-like qualities to multiple myeloma cells by inducing piRNA-823 expression and cancer cell-derived CSCs by reducing their stemness properties and inducing apoptosis (Wang et al., 2019). The drug is now undergoing phase III clinical trials to examine its preventive effect on bone metastasis in patients with advanced lung cancer (NCT02622607). CD47-targeting antibodies also overcome a key immune escape mechanism, the CD47/SIRP $\alpha$-mediated "Don't eat me" signal. ALX148, which is a CD47 blocking protein, was well tolerated in combination with anticancer antibodies and conventional chemotherapy in patients with advanced cancers (NCT03013218). Hu5F9-G4, an anti-CD47 antibody, also shows excellent tolerability and promising effects in leukemia stem cells in combination with Azacitidine (NCT03248479). These findings suggest that targeting CD47 with conventional cancer treatment may be a powerful strategy to address CSC-derived immune evasion. Ontak, a fusion protein comprized of human IL-2 and diphtheria toxin, targets $\mathrm{CD}^{2} 5^{+}$Treg cells by inducing apoptotic cell death (Cheung et al., 2019). A pilot study was carried out to evaluate its inhibitory effect on Tregs in metastatic pancreatic cancer patients (NCT00726037). This drug is designed to integrate DC vaccine administration for treating unresectable pancreatic cancer. Several clinical trials aiming at other immunotherapeutic targets, such as MDSCs and NK cells, are also ongoing (Table 1).

While direct CSC-targeted treatments such as NK, CAR$\mathrm{T}$ therapies and $\mathrm{DC}$ vaccines are still being studied, targeting the CSC niche might be a feasible immunological therapeutic approach to eradicate cancer, considering several encouraging preclinical results. Similarly, much effort will be required to resolve the side effects such as the resistance or diverse treatment responses that most immunotherapies may arouse. Additionally, basic research on the crosstalk between CSCs and their niche is also necessary for identifying a biomarker that can monitor the treatment response, as well as novel therapeutic targets for the development of effective treatments.

\section{AUTHOR CONTRIBUTIONS}

ML: conception and design, writing, review, and/or revision of the manuscript. TL: study supervision. Both authors contributed to the article and approved the submitted version.

\section{FUNDING}

The study was supported by the RGC General Research Fund (15102020), Collaborative Research Fund (C7026-18G), Health and Medical Research Fund (05161216), and Research Impact Fund (R5050-18F).

DNMT3B activation. Mol. Cancer 18:88. doi: 10.1186/s12943-0191011-5

Ai, L., Mu, S., Wang, Y., Wang, H., Cai, L., Li, W., et al. (2018). Prognostic role of myeloid-derived suppressor cells in cancers: a systematic review and meta-analysis. BMC Cancer 18:1220. doi: 10.1186/s12885-018-5086-y 
Alhabbab, R. Y. (2020). Targeting cancer stem cells by genetically engineered chimeric antigen receptor T cells. Front. Genet. 11:312. doi: 10.3389/fgene.2020. 00312

Al-Hajj, M., Wicha, M., Benito-Hernandez, A., Morrison, S., and Clarke, M. (2003). Prospective identification of tumorigenic breast cancer cells. Proc. Natl. Acad. Sci. U.S.A. 100, 3983-3988. doi: 10.1073/pnas. 1231735100

Almozyan, S., Colak, D., Mansour, F., Alaiya, A., Al-Harazi, O., Qattan, A., et al. (2017). PD-L1 promotes OCT4 and Nanog expression in breast cancer stem cells by sustaining PI3K/AKT pathway activation. Int. J. Cancer 141, 1402-1412. doi: 10.1002/ijc.30834

Alraouji, N. N., Al-Mohanna, F. H., Ghebeh, H., Arafah, M., Almeer, R., AlTweigeri, T., et al. (2020). Tocilizumab potentiates cisplatin cytotoxicity and targets cancer stem cells in triple-negative breast cancer. Mol. Carcinog. 59, 1041-1051. doi: 10.1002/mc.23234

Ames, E., Canter, R. J., Grossenbacher, S. K., Mac, S., Chen, M., Smith, R. C., et al. (2015a). NK Cells preferentially target tumor cells with a cancer stem cell phenotype. J. Immunol. 195, 4010-4019. doi: 10.4049/jimmunol.1500447

Ames, E., Canter, R. J., Grossenbacher, S. K., Mac, S., Smith, R. C., Monjazeb, A. M., et al. (2015b). Enhanced targeting of stem-like solid tumor cells with radiation and natural killer cells. Oncoimmunology 4:e1036212. doi: 10.1080/2162402X. 2015.1036212

Anguille, S., Smits, E. L., Lion, E., van Tendeloo, V. F., and Berneman, Z. N. (2014). Clinical use of dendritic cells for cancer therapy. Lancet Oncol. 15, e257-e267. doi: 10.1016/s1470-2045(13)70585-0

Barkal, A. A., Brewer, R. E., Markovic, M., Kowarsky, M., Barkal, S. A., Zaro, B. W., et al. (2019). CD24 signalling through macrophage Siglec-10 is a target for cancer immunotherapy. Nature 572, 392-396. doi: 10.1038/s41586-019-1456-0

Beck, B., Driessens, G., Goossens, S., Youssef, K. K., Kuchnio, A., Caauwe, A., et al. (2011). A vascular niche and a VEGF-Nrp1 loop regulate the initiation and stemness of skin tumours. Nature 478, 399-403. doi: 10.1038/nature10525

Bhatia, A., and Kumar, Y. (2016). Cancer stem cells and tumor immunoediting: putting two and two together. Expert Rev. Clin. Immunol. 12, 605-607. doi: 10.1586/1744666X.2016.1159133

Biller, B., and Dow, S. (2007). Immunotherapy of Cancer. Withrow \& MacEwen's Small Animal Clinical Oncology. St. Louis: Elsevier. 211-235.

Bocci, F., Levine, H., Onuchic, J. N., and Jolly, M. K. (2019). Deciphering the dynamics of epithelial-mesenchymal transition and cancer stem cells in tumor progression. Curr. Stem Cell Rep. 5, 11-21. doi: 10.1007/s40778-019-0150-3

Boks, M. A., Kager-Groenland, J. R., Haasjes, M. S., Zwaginga, J. J., van Ham, S. M., and ten Brinke, A. (2012). IL-10-generated tolerogenic dendritic cells are optimal for functional regulatory $\mathrm{T}$ cell induction-a comparative study of human clinical-applicable DC. Clin. Immunol. 142, 332-342. doi: 10.1016/j. clim.2011.11.011

Brissette, M. J., Lepage, S., Lamonde, A. S., Sirois, I., Groleau, J., Laurin, L. P., et al. (2012). MFG-E8 released by apoptotic endothelial cells triggers antiinflammatory macrophage reprogramming. PLoS One 7:e36368. doi: 10.1371/ journal.pone. 0036368

Brodaczewska, K. K., Szczylik, C., and Kieda, C. (2018). Immune consequences of anti-angiogenic therapyin renal cell carcinoma. Contemp. Oncol. (Pozn) 22, 14-22. doi: 10.5114/wo.2018.73878

Calderaro, J., Rousseau, B., Amaddeo, G., Mercey, M., Charpy, C., Costentin, C., et al. (2016). Programmed death ligand 1 expression in hepatocellular carcinoma: relationship With clinical and pathological features. Hepatology 64, 2038-2046. doi: 10.1002/hep.28710

Cassetta, L., and Kitamura, T. (2018). Targeting tumor-associated macrophages as a potential strategy to enhance the response to immune checkpoint inhibitors. Front. Cell Dev. Biol. 6:38. doi: 10.3389/fcell.2018.00038

Castriconi, R., Daga, A., Dondero, A., Zona, G., Poliani, P. L., Melotti, A., et al. (2009). NK cells recognize and kill human glioblastoma cells with stem cell-like properties. J. Immunol. 182, 3530-3539. doi: 10.4049/jimmunol.0 802845

Chan, L. C., Li, C. W., Xia, W., Hsu, J. M., Lee, H. H., Cha, J. H., et al. (2019). IL-6/JAK1 pathway drives PD-L1 Y112 phosphorylation to promote cancer immune evasion. J. Clin. Invest. 129, 3324-3338. doi: 10.1172/JCI126022

Chandra, D., Jahangir, A., Quispe-Tintaya, W., Einstein, M. H., and Gravekamp, C. (2013). Myeloid-derived suppressor cells have a central role in attenuated Listeria monocytogenes-based immunotherapy against metastatic breast cancer in young and old mice. Br. J. Cancer 108, 2281-2290. doi: 10.1038/bjc.2013.206
Cheever, M. A., and Higano, C. S. (2011). PROVENGE (Sipuleucel-T) in prostate cancer: the first FDA-approved therapeutic cancer vaccine. Clin. Cancer Res. 17, 3520-3526. doi: 10.1158/1078-0432.CCR-10-3126

Chen, X. H., Liu, Z. C., Zhang, G., Wei, W., Wang, X. X., Wang, H., et al. (2015). TGF-beta and EGF induced HLA-I downregulation is associated with epithelialmesenchymal transition (EMT) through upregulation of snail in prostate cancer cells. Mol. Immunol. 65, 34-42. doi: 10.1016/j.molimm.2014.12.017

Chen, Y., Song, Y., Du, W., Gong, L., Chang, H., and Zou, Z. (2019). Tumorassociated macrophages: an accomplice in solid tumor progression. J. Biomed. Sci. 26:78. doi: 10.1186/s12929-019-0568-z

Cheung, L. S., Fu, J., Kumar, P., Kumar, A., Urbanowski, M. E., Ihms, E. A., et al. (2019). Second-generation IL-2 receptor-targeted diphtheria fusion toxin exhibits antitumor activity and synergy with anti-PD-1 in melanoma. Proc. Natl. Acad. Sci. U.S.A. 116, 3100-3105. doi: 10.1073/pnas.1815087116

Chiu, D. K., Tse, A. P., Xu, I. M., Di Cui, J., Lai, R. K., Li, L. L., et al. (2017). Hypoxia inducible factor HIF-1 promotes myeloid-derived suppressor cells accumulation through ENTPD2/CD39L1 in hepatocellular carcinoma. Nat. Commun. 8:517. doi: 10.1038/s41467-017-00530-7

Chockley, P. J., Chen, J., Chen, G., Beer, D. G., Standiford, T. J., and Keshamouni, V. G. (2018). Epithelial-mesenchymal transition leads to NK cell-mediated metastasis-specific immunosurveillance in lung cancer. J. Clin. Invest. 128, 1384-1396. doi: 10.1172/JCI97611

Choi, H. S., Kim, J. H., Kim, S. L., and Lee, D. S. (2019). Disruption of the NFkappaB/IL-8 signaling axis by sulconazole inhibits human breast cancer stem cell formation. Cells 8:1007. doi: 10.3390/cells8091007

Chong, E. A., Melenhorst, J. J., Lacey, S. F., Ambrose, D. E., Gonzalez, V., Levine, B. L., et al. (2017). PD-1 blockade modulates chimeric antigen receptor (CAR)modified T cells: refueling the CAR. Blood 129, 1039-1041. doi: 10.1182/blood2016-09-738245

Cubillos-Ruiz, J. R., Martinez, D., Scarlett, U. K., Rutkowski, M. R., Nesbeth, Y. C., Camposeco-Jacobs, A. L., et al. (2010). CD277 is a negative co-stimulatory molecule universally expressed by ovarian cancer microenvironmental cells. Oncotarget 1, 329-338.

Cui, T. X., Kryczek, I., Zhao, L., Zhao, E., Kuick, R., Roh, M. H., et al. (2013). Myeloid-derived suppressor cells enhance stemness of cancer cells by inducing microRNA101 and suppressing the corepressor CtBP2. Immunity 39, 611-621. doi: 10.1016/j.immuni.2013.08.025

Di Ianni, M., Del Papa, B., De Ioanni, M., Moretti, L., Bonifacio, E., Cecchini, D., et al. (2008). Mesenchymal cells recruit and regulate T regulatory cells. Exp. Hematol. 36, 309-318. doi: 10.1016/j.exphem.2007.11.007

Dieci, M. V., Criscitiello, C., Goubar, A., Viale, G., Conte, P., Guarneri, V., et al. (2014). Prognostic value of tumor-infiltrating lymphocytes on residual disease after primary chemotherapy for triple-negative breast cancer: a retrospective multicenter study. Ann. Oncol. 25, 611-618. doi: 10.1093/annonc/mdt556

Facciabene, A., Peng, X., Hagemann, I. S., Balint, K., Barchetti, A., Wang, L. P., et al. (2011). Tumour hypoxia promotes tolerance and angiogenesis via CCL28 and T(reg) cells. Nature 475, 226-230. doi: 10.1038/nature10169

Fainaru, O., Shay, T., Hantisteanu, S., Goldenberg, D., Domany, E., and Groner, Y. (2007). TGFbeta-dependent gene expression profile during maturation of dendritic cells. Genes Immun. 8, 239-244. doi: 10.1038/sj.gene.6364380

Fang, W., Ye, L., Shen, L., Cai, J., Huang, F., Wei, Q., et al. (2014). Tumor-associated macrophages promote the metastatic potential of thyroid papillary cancer by releasing CXCL8. Carcinogenesis 35, 1780-1787. doi: 10.1093/carcin/bgu060

FDA (2017). FDA Approval Brings First Gene Therapy to the United States [Online]. Available online at: https://www.fda.gov/news-events/press-announcements/ fda-approval-brings-first-gene-therapy-united-states (accessed August 04, 2021).

Finn, R. S., Qin, S., Ikeda, M., Galle, P. R., Ducreux, M., Kim, T. Y., et al. (2020). Atezolizumab plus bevacizumab in unresectable hepatocellular carcinoma. N. Engl. J. Med. 382, 1894-1905. doi: 10.1056/NEJMoa1915745

Foster, A. E., Mahendravada, A., Shinners, N. P., Chang, W. C., Crisostomo, J., Lu, A., et al. (2017). Regulated expansion and survival of chimeric antigen receptormodified t cells using small molecule-dependent inducible MyD88/CD40. Mol. Ther. 25, 2176-2188. doi: 10.1016/j.ymthe.2017.06.014

Fourcade, J., Sun, Z., Benallaoua, M., Guillaume, P., Luescher, I. F., Sander, C., et al. (2010). Upregulation of Tim-3 and PD-1 expression is associated with tumor antigen-specific CD8+ T cell dysfunction in melanoma patients. J. Exp. Med. 207, 2175-2186. doi: 10.1084/jem.20100637 
Fridman, W. H., Galon, J., Pages, F., Tartour, E., Sautes-Fridman, C., and Kroemer, G. (2011). Prognostic and predictive impact of intra- and peritumoral immune infiltrates. Cancer Res. 71, 5601-5605. doi: 10.1158/0008-5472.CAN-11-1316

Galland, S., Vuille, J., Martin, P., Letovanec, I., Caignard, A., Fregni, G., et al. (2017). Tumor-derived mesenchymal stem cells use distinct mechanisms to block the activity of natural killer cell subsets. Cell Rep. 20, 2891-2905. doi: 10.1016/j.celrep.2017.08.089

Gao, L., Yu, S., and Zhang, X. (2014). Hypothesis: Tim-3/galectin-9, a new pathway for leukemia stem cells survival by promoting expansion of myeloid-derived suppressor cells and differentiating into tumor-associated macrophages. Cell Biochem. Biophys. 70, 273-277. doi: 10.1007/s12013-014-9900-0

Gao, X., Zhu, Y., Li, G., Huang, H., Zhang, G., Wang, F., et al. (2012). TIM-3 expression characterizes regulatory $\mathrm{T}$ cells in tumor tissues and is associated with lung cancer progression. PLoS One 7:e30676. doi: 10.1371/journal.pone. 0030676

Ginestier, C., Liu, S., Diebel, M. E., Korkaya, H., Luo, M., Brown, M., et al. (2010). CXCR1 blockade selectively targets human breast cancer stem cells in vitro and in xenografts. J. Clin. Invest. 120, 485-497. doi: 10.1172/JCI39397

Giuntoli, R. L., Lu, J., Kobayashi, H., Kennedy, R., and Celis, E. (2002). Direct costimulation of tumor-reactive CTL by helper T cells potentiate their proliferation, survival, and effector function. Clin. Cancer Res. 8, 922-931.

Goldstein, L. J., Perez, R. P., Yardley, D., Han, L. K., Reuben, J. M., Gao, H., et al. (2020). A window-of-opportunity trial of the CXCR $1 / 2$ inhibitor reparixin in operable HER-2-negative breast cancer. Breast Cancer Res. 22:4. doi: 10.1186/ s13058-019-1243-8

Guo, L., Cheng, X., Chen, H., Chen, C., Xie, S., Zhao, M., et al. (2019). Induction of breast cancer stem cells by M1 macrophages through Lin-28B-let-7-HMGA2 axis. Cancer Lett. 452, 213-225. doi: 10.1016/j.canlet.2019.03.032

Guo, Y., Feng, K., Wang, Y., and Han, W. (2018). Targeting cancer stem cells by using chimeric antigen receptor-modified $\mathrm{T}$ cells: a potential and curable approach for cancer treatment. Protein Cell 9, 516-526. doi: 10.1007/s13238017-0394-6

Heczey, A., Louis, C. U., Savoldo, B., Dakhova, O., Durett, A., Grilley, B., et al. (2017). CAR T cells administered in combination with lymphodepletion and PD-1 inhibition to patients with neuroblastoma. Mol. Ther. 25, 2214-2224. doi: 10.1016/j.ymthe.2017.05.012

Hsu, J. M., Xia, W., Hsu, Y. H., Chan, L. C., Yu, W. H., Cha, J. H., et al. (2018). STT3-dependent PD-L1 accumulation on cancer stem cells promotes immune evasion. Nat. Commun. 9:1908. doi: 10.1038/s41467-018-04313-6

Huang, B. Y., Zhan, Y. P., Zong, W. J., Yu, C. J., Li, J. F., Qu, Y. M., et al. (2015). The PD-1/B7-H1 pathway modulates the natural killer cells versus mouse glioma stem cells. PLoS One 10:e0134715. doi: 10.1371/journal.pone.0134715

Huergo-Zapico, L., Parodi, M., Cantoni, C., Lavarello, C., Fernandez-Martinez, J. L., Petretto, A., et al. (2018). NK-cell editing mediates epithelial-tomesenchymal transition via phenotypic and proteomic changes in melanoma cell lines. Cancer Res. 78, 3913-3925. doi: 10.1158/0008-5472.CAN-17-1891

Idos, G. E., Kwok, J., Bonthala, N., Kysh, L., Gruber, S. B., and Qu, C. (2020). The prognostic implications of tumor infiltrating lymphocytes in colorectal cancer: a systematic review and meta-analysis. Sci. Rep. 10:3360. doi: 10.1038/s41598020-60255-4

Iliopoulos, D., Hirsch, H. A., and Struhl, K. (2009). An epigenetic switch involving NF-kappaB, Lin28, Let-7 MicroRNA, and IL6 links inflammation to cell transformation. Cell 139, 693-706. doi: 10.1016/j.cell.2009.10.014

Imai, K., Matsuyama, S., Miyake, S., Suga, K., and Nakachi, K. (2000). Natural cytotoxic activity of peripheral-blood lymphocytes and cancer incidence: an 11-year follow-up study of a general population. Lancet 356, 1795-1799. doi: 10.1016/s0140-6736(00)03231-1

Jachetti, E., Caputo, S., Mazzoleni, S., Brambillasca, C. S., Parigi, S. M., Grioni, M., et al. (2015). Tenascin-C protects cancer stem-like cells from immune surveillance by arresting T-cell activation. Cancer Res. 75, 2095-2108. doi: 10. 1158/0008-5472.CAN-14-2346

Jinushi, M., Chiba, S., Yoshiyama, H., Masutomi, K., Kinoshita, I., Dosaka-Akita, H., et al. (2011). Tumor-associated macrophages regulate tumorigenicity and anticancer drug responses of cancer stem/initiating cells. Proc. Natl. Acad. Sci. U.S.A. 108, 12425-12430. doi: 10.1073/pnas.1106 645108

Katoh, M. (2017). Canonical and non-canonical WNT signaling in cancer stem cells and their niches: cellular heterogeneity, omics reprogramming, targeted therapy and tumor plasticity. Int. J. Oncol. 51, 1357-1369. doi: 10.3892/ijo.2017. 4129

Kikushige, Y., Shima, T., Takayanagi, S., Urata, S., Miyamoto, T., Iwasaki, H., et al. (2010). TIM-3 is a promising target to selectively kill acute myeloid leukemia stem cells. Cell Stem Cell 7, 708-717. doi: 10.1016/j.stem.2010.11.014

Kloss, C. C., Lee, J., Zhang, A., Chen, F., Melenhorst, J. J., Lacey, S. F., et al. (2018). Dominant-negative TGF-beta receptor enhances PSMA-targeted human CAR T cell proliferation and augments prostate cancer eradication. Mol. Ther. 26, 1855-1866. doi: 10.1016/j.ymthe.2018.05.003

Knochelmann, H. M., Dwyer, C. J., Bailey, S. R., Amaya, S. M., Elston, D. M., Mazza-McCrann, J. M., et al. (2018). When worlds collide: Th17 and Treg cells in cancer and autoimmunity. Cell Mol. Immunol. 15, 458-469. doi: 10.1038/ s41423-018-0004-4

Kobie, J., Wu, R., Kurt, R., Lou, S., Adelman, M., Whitesell, L., et al. (2003). Transforming growth factor $\beta$ inhibits the antigen-presenting functions and antitumor activity of dendritic cell vaccines. Cancer Res. 63, $1860-1864$.

Komura, N., Mabuchi, S., Shimura, K., Yokoi, E., Kozasa, K., Kuroda, H., et al. (2020). The role of myeloid-derived suppressor cells in increasing cancer stem-like cells and promoting PD-L1 expression in epithelial ovarian cancer. Cancer Immunol. Immunother. 69, 2477-2499. doi: 10.1007/s00262020-02628-2

Koreth, J., Kim, H. T., Jones, K. T., Lange, P. B., Reynolds, C. G., Chammas, M. J., et al. (2016). Efficacy, durability, and response predictors of low-dose interleukin-2 therapy for chronic graft-versus-host disease. Blood 128, 130-137. doi: 10.1182/blood-2016-02-702852

Krempski, J., Karyampudi, L., Behrens, M. D., Erskine, C. L., Hartmann, L., Dong, H., et al. (2011). Tumor-infiltrating programmed death receptor-1+ dendritic cells mediate immune suppression in ovarian cancer. J. Immunol. 186, 6905-6913. doi: 10.4049/jimmunol.1100274

Kumar, S., Wilkes, D. W., Samuel, N., Blanco, M. A., Nayak, A., Alicea-Torres, K., et al. (2018). DeltaNp63-driven recruitment of myeloid-derived suppressor cells promotes metastasis in triple-negative breast cancer. J. Clin. Invest. 128, 5095-5109. doi: 10.1172/JCI99673

Kurebayashi, Y., Ojima, H., Tsujikawa, H., Kubota, N., Maehara, J., Abe, Y., et al. (2018). Landscape of immune microenvironment in hepatocellular carcinoma and its additional impact on histological and molecular classification. Hepatology 68, 1025-1041. doi: 10.1002/hep.29904

Kusmartsev, S., Nefedova, Y., Yoder, D., and Gabrilovich, D. I. (2004). Antigenspecific inhibition of CD8 $+\mathrm{T}$ cell response by immature myeloid cells in cancer is mediated by reactive oxygen species. J. Immunol. 172, 989-999. doi: 10.4049/ jimmunol.172.2.989

Lee, T. K., Cheung, V. C., Lu, P., Lau, E. Y., Ma, S., Tang, K. H., et al. (2014). Blockade of CD47-mediated cathepsin S/protease-activated receptor 2 signaling provides a therapeutic target for hepatocellular carcinoma. Hepatology 60 , 179-191. doi: 10.1002/hep.27070

Lewis, C. E., and Pollard, J. W. (2006). Distinct role of macrophages in different tumor microenvironments. Cancer Res. 66, 605-612. doi: 10.1158/0008-5472. CAN-05-4005

Li, Y., Wang, L., Pappan, L., Galliher-Beckley, A., and Shi, J. (2012). IL-1ß promotes stemness and invasiveness of colon cancer cells through Zeb1 activation. Mol. Cancer 11:87. doi: 10.1186/1476-4598-11-87

Liu, F., Liu, Y., and Chen, Z. (2018). Tim-3 expression and its role in hepatocellular carcinoma. J. Hematol. Oncol. 11:126. doi: 10.1186/s13045-018-0667-4

Liu, S., Zhang, C., Wang, B., Zhang, H., Qin, G., Li, C., et al. (2021). Regulatory T cells promote glioma cell stemness through TGF-beta-NF-kappaB-IL6-STAT3 signaling. Cancer Immunol. Immunother. doi: 10.1007/s00262-021-02872-0 [Epub ahead of print].

Liu, X., Kwon, H., Li, Z., and Fu, Y. X. (2017). Is CD47 an innate immune checkpoint for tumor evasion? J. Hematol. Oncol. 10:12. doi: 10.1186/s13045016-0381-z

Lopez-Soto, A., Huergo-Zapico, L., Galvan, J. A., Rodrigo, L., de Herreros, A. G., Astudillo, A., et al. (2013). Epithelial-mesenchymal transition induces an antitumor immune response mediated by NKG2D receptor. J. Immunol. 190, 4408-4419. doi: 10.4049/jimmunol.1202950

Lu, H., Clauser, K. R., Tam, W. L., Frose, J., Ye, X., Eaton, E. N., et al. (2014). A breast cancer stem cell niche supported by juxtacrine signalling from monocytes and macrophages. Nat. Cell Biol. 16, 1105-1117. doi: 10.1038/ncb3041 
Luo, H., Zeng, C., Fang, C., Seeruttun, S. R., Lv, L., and Wang, W. (2014). A new strategy using ALDHhigh-CD8+T cells to inhibit tumorigenesis. PLoS One 9:e103193. doi: 10.1371/journal.pone.0103193

Ma, Y., Shurin, G. V., Peiyuan, Z., and Shurin, M. R. (2013). Dendritic cells in the cancer microenvironment. J. Cancer 4, 36-44. doi: 10.7150/jca.5046

Ma, Z., and Ji, J. (2020). N6-methyladenosine (m6A) RNA modification in cancer stem cells. Stem Cells 38, 1511-1519. doi: 10.1002/stem.3279

Malaer, J. D., and Mathew, P. A. (2020). Role of LLT1 and PCNA as natural killer cell immune evasion strategies of HCT 116 cells. Anticancer Res. 40, 6613-6621. doi: 10.21873/anticanres.14686

Malfitano, A. M., Pisanti, S., Napolitano, F., Di Somma, S., Martinelli, R., and Portella, G. (2020). Tumor-associated macrophage status in cancer treatment. Cancers (Basel) 12:1987. doi: 10.3390/cancers12071987

Maniati, E., Soper, R., and Hagemann, T. (2010). Up for Mischief? IL-17/Th17 in the tumour microenvironment. Oncogene 29, 5653-5662. doi: 10.1038/onc. 2010.367

Mansour, F. A., Al-Mazrou, A., Al-Mohanna, F., Al-Alwan, M., and Ghebeh, H. (2020). PD-L1 is overexpressed on breast cancer stem cells through notch3/mTOR axis. Oncoimmunology 9:1729299. doi: 10.1080/2162402X.2020. 1729299

Marshall, E. A., Ng, K. W., Kung, S. H., Conway, E. M., Martinez, V. D., Halvorsen, E. C., et al. (2016). Emerging roles of T helper 17 and regulatory T cells in lung cancer progression and metastasis. Mol. Cancer 15:67. doi: 10.1186/s12943016-0551-1

Miao, Y., Yang, H., Levorse, J., Yuan, S., Polak, L., Sribour, M., et al. (2019). Adaptive immune resistance emerges from tumor-initiating stem cells. Cell 177, 1172-1186.e4. doi: 10.1016/j.cell.2019.03.025

Mima, K., Okabe, H., Ishimoto, T., Hayashi, H., Nakagawa, S., Kuroki, H., et al. (2012). CD44s regulates the TGF-beta-mediated mesenchymal phenotype and is associated with poor prognosis in patients with hepatocellular carcinoma. Cancer Res. 72, 3414-3423. doi: 10.1158/0008-5472.CAN-12-0299

Mitchem, J. B., Brennan, D. J., Knolhoff, B. L., Belt, B. A., Zhu, Y., Sanford, D. E., et al. (2013). Targeting tumor-infiltrating macrophages decreases tumorinitiating cells, relieves immunosuppression, and improves chemotherapeutic responses. Cancer Res. 73, 1128-1141. doi: 10.1158/0008-5472.CAN-12-2731

Mou, W., Xu, Y., Ye, Y., Chen, S., Li, X., Gong, K., et al. (2015). Expression of Sox2 in breast cancer cells promotes the recruitment of M2 macrophages to tumor microenvironment. Cancer Lett. 358, 115-123. doi: 10.1016/j.canlet.2014.11. 004

Nagaraj, S., and Gabrilovich, D. (2010). Myeloid-Derived Suppressor Cells in Human Cancer. Cancer J. 16, 348-353. doi: 10.1097/PPO.0b013e3181eb3358

Napoletano, C., Bellati, F., Ruscito, I., Pernice, M., Zizzari, I. G., Caponnetto, S., et al. (2016). Immunological and clinical impact of cancer stem cells in vulvar cancer: role of CD133/CD24/ABCG2-expressing cells. Anticancer Res. 36, 5109-5116. doi: 10.21873/anticanres. 11080

Nnv, R., and Kundu, G. C. (2018). Role of tumour associated macrophages (TAMs) in regulation of cancer stem cell (CSCs) enrichment in breast cancer. ESMO Open 3, A1-A463. doi: 10.1136/esmoopen-2018-EACR25.316

Ostrand-Rosenberg, S. (2010). Myeloid-derived suppressor cells: more mechanisms for inhibiting antitumor immunity. Cancer Immunol. Immunother. 59, 1593-1600. doi: 10.1007/s00262-010-0855-8

Ouzounova, M., Lee, E., Piranlioglu, R., El Andaloussi, A., Kolhe, R., Demirci, M. F., et al. (2017). Monocytic and granulocytic myeloid derived suppressor cells differentially regulate spatiotemporal tumour plasticity during metastatic cascade. Nat. Commun. 8:14979. doi: 10.1038/ncomms14979

Paluskievicz, C. M., Cao, X., Abdi, R., Zheng, P., Liu, Y., and Bromberg, J. S. (2019). $\mathrm{T}$ regulatory cells and priming the suppressive tumor microenvironment. Front. Immunol. 10:2453. doi: 10.3389/fimmu.2019.02453

Pan, Q., Li, Q., Liu, S., Ning, N., Zhang, X., Xu, Y., et al. (2015). Concise review: targeting cancer stem cells using immunologic approaches. Stem Cells 33, 2085-2092. doi: 10.1002/stem.2039

Pang, Y. B., He, J., Cui, B. Y., Xu, S., Li, X. L., Wu, M. Y., et al. (2019). A potential antitumor effect of dendritic cells fused with cancer stem cells in hepatocellular carcinoma. Stem Cells Int. 2019:5680327. doi: 10.1155/2019/5680327

Panni, R. Z., Sanford, D. E., Belt, B. A., Mitchem, J. B., Worley, L. A., Goetz, B. D., et al. (2014). Tumor-induced STAT3 activation in monocytic myeloidderived suppressor cells enhances stemness and mesenchymal properties in human pancreatic cancer. Cancer Immunol. Immunother. 63, 513-528. doi: 10.1007/s00262-014-1527-x

Papaccio, F., Paino, F., Regad, T., Papaccio, G., Desiderio, V., and Tirino, V. (2017). Concise review: cancer cells, cancer stem cells, and mesenchymal stem cells: influence in cancer development. Stem Cells Transl. Med. 6, 2115-2125. doi: 10.1002/sctm.17-0138

Pardee, A. D., Shi, J., and Butterfield, L. H. (2014). Tumor-derived alphafetoprotein impairs the differentiation and T cell stimulatory activity of human dendritic cells. J. Immunol. 193, 5723-5732. doi: 10.4049/jimmunol.1400725

Peng, D., Tanikawa, T., Li, W., Zhao, L., Vatan, L., Szeliga, W., et al. (2016). Myeloid-derived suppressor cells endow stem-like qualities to breast cancer cells through IL6/STAT3 and NO/NOTCH cross-talk signaling. Cancer Res. 76, 3156-3165. doi: 10.1158/0008-5472.CAN-15-2528

Pietra, G., Manzini, C., Vitale, M., Balsamo, M., Ognio, E., Boitano, M., et al. (2009). Natural killer cells kill human melanoma cells with characteristics of cancer stem cells. Int. Immunol. 21, 793-801. doi: 10.1093/intimm/dxp047

Pittari, G., Filippini, P., Gentilcore, G., Grivel, J. C., and Rutella, S. (2015). Revving up natural killer cells and cytokine-induced killer cells against hematological malignancies. Front. Immunol. 6:230. doi: 10.3389/fimmu.2015.00230

Raggi, C., Mousa, H. S., Correnti, M., Sica, A., and Invernizzi, P. (2016). Cancer stem cells and tumor-associated macrophages: a roadmap for multitargeting strategies. Oncogene 35, 671-682. doi: 10.1038/onc.2015.132

Ravindran, S., Rasool, S., and Maccalli, C. (2019). The cross talk between cancer stem cells/cancer initiating cells and tumor microenvironment: the missing piece of the puzzle for the efficient targeting of these cells with immunotherapy. Cancer Microenviron. 12, 133-148. doi: 10.1007/s12307-019-00233-1

Rezalotfi, A., Ahmadian, E., Aazami, H., Solgi, G., and Ebrahimi, M. (2019). Gastric cancer stem cells effect on Th17/Treg balance; A bench to beside perspective. Front. Oncol. 9:226. doi: 10.3389/fonc.2019.00226

Rinkenbaugh, A. L., and Baldwin, A. S. (2016). The NF-kappaB pathway and cancer stem cells. Cells 5:16. doi: 10.3390/cells5020016

Ruffini, P. A. (2019). The CXCL8-CXCR1/2 axis as a therapeutic target in breast cancer stem-like cells. Front. Oncol. 9:40. doi: 10.3389/fonc.2019.00040

Ruiz de Galarreta, M., Bresnahan, E., Molina-Sanchez, P., Lindblad, K. E., Maier, B., Sia, D., et al. (2019). beta-catenin activation promotes immune escape and resistance to Anti-PD-1 therapy in hepatocellular carcinoma. Cancer Discov. 9, 1124-1141. doi: 10.1158/2159-8290.CD-19-0074

Sainz, B. Jr., Carron, E., Vallespinos, M., and Machado, H. L. (2016). Cancer stem cells and macrophages: implications in tumor biology and therapeutic strategies. Mediators Inflamm. 2016:9012369. doi: 10.1155/2016/9012369

Sakaguchi, S., Miyara, M., Costantino, C., and Hafler, D. (2010). FOXP3+ regulatory $\mathrm{T}$ cells in the human immune system. Nat. Rev. Immunol. 10, 490-500. doi: 10.1038/nri2785

Schatton, T., Schutte, U., Frank, N. Y., Zhan, Q., Hoerning, A., Robles, S. C., et al. (2010). Modulation of T-cell activation by malignant melanoma initiating cells. Cancer Res. 70, 697-708. doi: 10.1158/0008-5472.CAN-09-1592

Schott, A. F., Goldstein, L. J., Cristofanilli, M., Ruffini, P. A., McCanna, S., Reuben, J. M., et al. (2017). Phase Ib pilot study to evaluate reparixin in combination with weekly paclitaxel in patients with HER-2-Negative metastatic breast cancer. Clin. Cancer Res. 23, 5358-5365. doi: 10.1158/1078-0432.CCR-16-2748

She, M., Niu, X., Chen, X., Li, J., Zhou, M., He, Y., et al. (2012). Resistance of leukemic stem-like cells in AML cell line KG1a to natural killer cell-mediated cytotoxicity. Cancer Lett. 318, 173-179. doi: 10.1016/j.canlet.2011.12.017

Shi, T., Ma, Y., Yu, L., Jiang, J., Shen, S., Hou, Y., et al. (2018). Cancer immunotherapy: a focus on the regulation of immune checkpoints. Int. J. Mol. Sci. 19:1389. doi: 10.3390/ijms19051389

Shibue, T., and Weinberg, R. A. (2017). EMT, CSCs, and drug resistance: the mechanistic link and clinical implications. Nat. Rev. Clin. Oncol. 14, 611-629. doi: 10.1038/nrclinonc.2017.44

Shipitsin, M., Campbell, L. L., Argani, P., Weremowicz, S., Bloushtain-Qimron, N., Yao, J., et al. (2007). Molecular definition of breast tumor heterogeneity. Cancer Cell 11, 259-273. doi: 10.1016/j.ccr.2007.01.013

Solis-Castillo, L. A., Garcia-Romo, G. S., Diaz-Rodriguez, A., Reyes-Hernandez, D., Tellez-Rivera, E., Rosales-Garcia, V. H., et al. (2020). Tumor-infiltrating regulatory $\mathrm{T}$ cells, CD8/Treg ratio, and cancer stem cells are correlated with lymph node metastasis in patients with early breast cancer. Breast Cancer 27, 837-849. doi: 10.1007/s12282-020-01079-y 
Spranger, S., Dai, D., Horton, B., and Gajewski, T. F. (2017). Tumor-residing Batf3 dendritic cells are required for effector $\mathrm{T}$ cell trafficking and adoptive $\mathrm{T}$ cell therapy. Cancer Cell 31, 711-723.e4. doi: 10.1016/j.ccell.2017.04.003

Stein, R. G., Ebert, S., Schlahsa, L., Scholz, C. J., Braun, M., Hauck, P., et al. (2019). Cognate nonlytic interactions between CD8(+) T cells and breast cancer cells induce cancer stem cell-like properties. Cancer Res. 79, 1507-1519. doi: 10.1158/0008-5472.CAN-18-0387

Su, R., Dong, L., Li, Y., Gao, M., Han, L., Wunderlich, M., et al. (2020). Targeting FTO suppresses cancer stem cell maintenance and Immune evasion. Cancer Cell 38, 79-96.e11. doi: 10.1016/j.ccell.2020.04.017

Sultan, M., Coyle, K. M., Vidovic, D., Thomas, M. L., Gujar, S., and Marcato, P. (2017). Hide-and-seek: the interplay between cancer stem cells and the immune system. Carcinogenesis 38, 107-118. doi: 10.1093/carcin/bgw115

Szarynska, M., Olejniczak, A., Kobiela, J., Laski, D., Sledzinski, Z., and Kmiec, Z. (2018). Cancer stem cells as targets for DC-based immunotherapy of colorectal cancer. Sci. Rep. 8:12042. doi: 10.1038/s41598-018-30525-3

Tallerico, R., Garofalo, C., and Carbone, E. (2016). A new biological feature of natural killer cells: the recognition of solid tumor-derived cancer stem cells. Front. Immunol. 7:179. doi: 10.3389/fimmu.2016.00179

Tallerico, R., Todaro, M., Di Franco, S., Maccalli, C., Garofalo, C., Sottile, R., et al. (2013). Human NK cells selective targeting of colon cancer-initiating cells: a role for natural cytotoxicity receptors and MHC class I molecules. J. Immunol. 190, 2381-2390. doi: 10.4049/jimmunol.1201542

Taniguchi, H., Suzuki, Y., and Natori, Y. (2019). The evolving landscape of cancer stem cells and ways to overcome cancer heterogeneity. Cancers (Basel) 11:532. doi: $10.3390 /$ cancers 11040532

Todaro, M., Alea, M. P., Di Stefano, A. B., Cammareri, P., Vermeulen, L., Iovino, F., et al. (2007). Colon cancer stem cells dictate tumor growth and resist cell death by production of interleukin-4. Cell Stem Cell 1, 389-402. doi: 10.1016/j. stem.2007.08.001

Treps, L., Perret, R., Edmond, S., Ricard, D., and Gavard, J. (2017). Glioblastoma stem-like cells secrete the pro-angiogenic VEGF-A factor in extracellular vesicles. J. Extracell. Vesicles 6:1359479. doi: 10.1080/20013078.2017.1359479

Tseng, H. C., Arasteh, A., Paranjpe, A., Teruel, A., Yang, W., Behel, A., et al. (2010). Increased lysis of stem cells but not their differentiated cells by natural killer cells; de-differentiation or reprogramming activates NK cells. PLoS One 5:e11590. doi: 10.1371/journal.pone.0011590

Tsuchiya, H., and Shiota, G. (2021). Immune evasion by cancer stem cells. Regen. Ther. 17, 20-33. doi: 10.1016/j.reth.2021.02.006

Visvader, J. E., and Lindeman, G. J. (2008). Cancer stem cells in solid tumours: accumulating evidence and unresolved questions. Nat. Rev. Cancer 8, 755-768. doi: $10.1038 / \mathrm{nrc} 2499$

Walker, J. D., Sehgal, I., and Kousoulas, K. G. (2011). Oncolytic herpes simplex virus 1 encoding 15-prostaglandin dehydrogenase mitigates immune suppression and reduces ectopic primary and metastatic breast cancer in mice. J. Virol. 85, 7363-7371. doi: 10.1128/JVI.00098-11

Wan, S., Zhao, E., Kryczek, I., Vatan, L., Sadovskaya, A., Ludema, G., et al. (2014). Tumor-associated macrophages produce interleukin 6 and signal via STAT3 to promote expansion of human hepatocellular carcinoma stem cells. Gastroenterology 147, 1393-1404. doi: 10.1053/j.gastro.2014.08.039

Wang, B., Wang, Q., Wang, Z., Jiang, J., Yu, S. C., Ping, Y. F., et al. (2014). Metastatic consequences of immune escape from NK cell cytotoxicity by human breast cancer stem cells. Cancer Res. 74, 5746-5757. doi: 10.1158/0008-5472. CAN-13-2563

Wang, D., Fu, L., Sun, H., Guo, L., and DuBois, R. N. (2015). Prostaglandin E2 promotes colorectal cancer stem cell expansion and metastasis in mice. Gastroenterology 149, 1884-1895.e4. doi: 10.1053/j.gastro.2015.07.064

Wang, D., Xu, J., Liu, B., He, X., Zhou, L., Hu, X., et al. (2018a). IL6 blockade potentiates the anti-tumor effects of gamma-secretase inhibitors in Notch3expressing breast cancer. Cell Death Differ. 25, 330-339. doi: 10.1038/cdd.2017. 162

Wang, F., Lau, J. K. C., and Yu, J. (2021). The role of natural killer cell in gastrointestinal cancer: killer or helper. Oncogene 40, 717-730. doi: 10.1038/ s41388-020-01561-Z

Wang, L., Liu, Y., Zhou, Y., Wang, J., Tu, L., Sun, Z., et al. (2019). Zoledronic acid inhibits the growth of cancer stem cell derived from cervical cancer cell by attenuating their stemness phenotype and inducing apoptosis and cell cycle arrest through the Erk1/2 and Akt pathways. J. Exp. Clin. Cancer Res. 38:93. doi: 10.1186/s13046-019-1109-z
Wang, Y., Chen, M., Wu, Z., Tong, C., Dai, H., Guo, Y., et al. (2018b). CD133-directed CAR $\mathrm{T}$ cells for advanced metastasis malignancies: a phase I trial. Oncoimmunology 7:e1440169. doi: 10.1080/2162402X.2018. 1440169

Wei, F., Zhang, T., Deng, S. C., Wei, J. C., Yang, P., Wang, Q., et al. (2019). PD-L1 promotes colorectal cancer stem cell expansion by activating HMGA1dependent signaling pathways. Cancer Lett. 450, 1-13. doi: 10.1016/j.canlet. 2019.02.022

Wei, J., Barr, J., Kong, L. Y., Wang, Y., Wu, A., Sharma, A. K., et al. (2010). Gliomaassociated cancer-initiating cells induce immunosuppression. Clin. Cancer Res. 16, 461-473. doi: 10.1158/1078-0432.CCR-09-1983

Wei, J., Wu, A., Kong, L. Y., Wang, Y., Fuller, G., Fokt, I., et al. (2011). Hypoxia potentiates glioma-mediated immunosuppression. PLoS One 6:e16195. doi: 10. 1371/journal.pone. 0016195

Wei, L., Laurence, A., and O'Shea, J. J. (2008). New insights into the roles of Stat5a/b and Stat 3 in T cell development and differentiation. Semin. Cell Dev. Biol. 19, 394-400. doi: 10.1016/j.semcdb.2008.07.011

Wei, X., Yang, S., Pu, X., He, S., Yang, Z., Sheng, X., et al. (2019). Tumor-associated macrophages increase the proportion of cancer stem cells in lymphoma by secreting pleiotrophin. Am. J. Transl. Res. 11, 6393-6402.

Welte, T., Kim, I. S., Tian, L., Gao, X., Wang, H., Li, J., et al. (2016). Oncogenic mTOR signalling recruits myeloid-derived suppressor cells to promote tumour initiation. Nat. Cell Biol. 18, 632-644. doi: 10.1038/ncb3355

Werno, C., Menrad, H., Weigert, A., Dehne, N., Goerdt, S., Schledzewski, K., et al. (2010). Knockout of HIF-1alpha in tumor-associated macrophages enhances M2 polarization and attenuates their pro-angiogenic responses. Carcinogenesis 31, 1863-1872. doi: 10.1093/carcin/bgq088

Xiang, T., Long, H., He, L., Han, X., Lin, K., Liang, Z., et al. (2015). Interleukin17 produced by tumor microenvironment promotes self-renewal of $\mathrm{CD} 133+$ cancer stem-like cells in ovarian cancer. Oncogene 34, 165-176. doi: 10.1038/ onc. 2013.537

Xiao, P., Long, X., Zhang, L., Ye, Y., Guo, J., Liu, P., et al. (2018). Neurotensin/IL8 pathway orchestrates local inflammatory response and tumor invasion by inducing M2 polarization of Tumor-associated macrophages and epithelialmesenchymal transition of hepatocellular carcinoma cells. Oncoimmunology 7:e1440166. doi: 10.1080/2162402X.2018.1440166

Xu, M., Zhao, Z., Song, J., Lan, X., Lu, S., Chen, M., et al. (2017). Interactions between interleukin- 6 and myeloid-derived suppressor cells drive the chemoresistant phenotype of hepatocellular cancer. Exp. Cell Res. 351, 142-149. doi: 10.1016/j.yexcr.2017.01.008

Yamashita, T., Ji, J., Budhu, A., Forgues, M., Yang, W., Wang, H. Y., et al. (2009). EpCAM-positive hepatocellular carcinoma cells are tumor-initiating cells with stem/progenitor cell features. Gastroenterology 136, 1012-1024. doi: 10.1053/j. gastro.2008.12.004

Yang, J., Liao, D., Chen, C., Liu, Y., Chuang, T. H., Xiang, R., et al. (2013). Tumorassociated macrophages regulate murine breast cancer stem cells through a novel paracrine EGFR/Stat3/Sox-2 signaling pathway. Stem Cells 31, 248-258. doi: 10.1002/stem.1281

Yang, L., Dong, Y., Li, Y., Wang, D., Liu, S., Wang, D., et al. (2019). IL-10 derived from M2 macrophage promotes cancer stemness via JAK1/STAT1/NFkappaB/Notch1 pathway in non-small cell lung cancer. Int. J. Cancer 145, 1099-1110. doi: 10.1002/ijc.32151

Yang, S., Wang, B., Guan, C., Wu, B., Cai, C., Wang, M., et al. (2011). Foxp3+IL$17+\mathrm{T}$ cells promote development of cancer-initiating cells in colorectal cancer. J. Leukoc. Biol. 89, 85-91. doi: 10.1189/jlb.0910506

Yang, X., Wang, D., Lin, J., Yang, X., and Zhao, H. (2020). Atezolizumab plus bevacizumab for unresectable hepatocellular carcinoma. Lancet Oncol. 21:e412. doi: 10.1016/S1470-2045(20)30430-7

Yi, H., Cho, H. J., Cho, S. M., Jo, K., Park, J. A., Kim, N. H., et al. (2012). Blockade of interleukin-6 receptor suppresses the proliferation of $\mathrm{H} 460$ lung cancer stem cells. Int. J. Oncol. 41, 310-316. doi: 10.3892/ijo.2012.1447

Yi, L., Xiao, H., Xu, M., Ye, X., Hu, J., Li, F., et al. (2011). Glioma-initiating cells: a predominant role in microglia/macrophages tropism to glioma. J. Neuroimmunol. 232, 75-82. doi: 10.1016/j.jneuroim.2010.10.011

Yin, T., Wang, G., He, S., Liu, Q., Sun, J., and Wang, Y. (2016). Human cancer cells with stem cell-like phenotype exhibit enhanced sensitivity to the cytotoxicity of IL-2 and IL-15 activated natural killer cells. Cell Immunol. 300, 41-45. doi: 10.1016/j.cellimm.2015.11.009 
$\mathrm{Yu}, \mathrm{X} ., \mathrm{Li}, \mathrm{H}$. , and Ren, X. (2012). Interaction between regulatory T cells and cancer stem cells. Int. J. Cancer 131, 1491-1498. doi: 10.1002/ijc.27634

Zhang, B. L., Li, D., Gong, Y. L., Huang, Y., Qin, D. Y., Jiang, L., et al. (2019). Preclinical evaluation of chimeric antigen receptor-modified $\mathrm{T}$ cells specific to epithelial cell adhesion molecule for treating colorectal cancer. Hum. Gene. Ther. 30, 402-412. doi: 10.1089/hum.2018.229

Zhang, C., Hu, Y., and Shi, C. (2020a). Targeting natural killer cells for tumor immunotherapy. Front. Immunol. 11:60. doi: 10.3389/fimmu.2020.00060

Zhang, C., Wang, H., Wang, X., Zhao, C., and Wang, H. (2020b). CD44, a marker of cancer stem cells, is positively correlated with PD-L1 expression and immune cells infiltration in lung adenocarcinoma. Cancer Cell Int. 20:583. doi: 10.1186/ s12935-020-01671-4

Zheng, F., Dang, J., Zhang, H., Xu, F., Ba, D., Zhang, B., et al. (2018). Cancer stem cell vaccination with PD-L1 and CTLA-4 blockades enhances the eradication of melanoma stem cells in a mouse tumor model. J. Immunother. 41, 361-368. doi: 10.1097/CJI.0000000000000242

Zhong, M., Zhong, C., Cui, W., Wang, G., Zheng, G., Li, L., et al. (2019). Induction of tolerogenic dendritic cells by activated TGF-beta/Akt/Smad2 signaling in RIG-I-deficient stemness-high human liver cancer cells. BMC Cancer 19:439. doi: 10.1186/s12885-019-5670-9
Zhou, W., Ke, S. Q., Huang, Z., Flavahan, W., Fang, X., Paul, J., et al. (2015). Periostin secreted by glioblastoma stem cells recruits M2 tumour-associated macrophages and promotes malignant growth. Nat. Cell. Biol. 17, 170-182. doi: $10.1038 / \mathrm{ncb} 3090$

Zhu, X., Prasad, S., Gaedicke, S., Hettich, M., Firat, E., and Niedermann, G. (2015). Patient-derived glioblastoma stem cells are killed by CD133- specific CAR T cells but induce the T cell aging marker CD57. Oncotarget 6, 171-184. doi: 10.18632/oncotarget.2767

Conflict of Interest: The authors declare that the research was conducted in the absence of any commercial or financial relationships that could be construed as a potential conflict of interest.

Copyright (0) 2021 Lei and Lee. This is an open-access article distributed under the terms of the Creative Commons Attribution License (CC BY). The use, distribution or reproduction in other forums is permitted, provided the original author(s) and the copyright owner(s) are credited and that the original publication in this journal is cited, in accordance with accepted academic practice. No use, distribution or reproduction is permitted which does not comply with these terms. 